Check for updates

Cite this: RSC Adv., 2019, 9, 15410

Received 7th March 2019

Accepted 20th April 2019

DOI: 10.1039/c9ra01750j

rsc.li/rsc-advances

\section{BODIPY derivatives with near infra-red absorption as small molecule donors for bulk heterojunction solar cells $\dagger$}

\author{
John Marques dos Santos,,$^{\mathrm{a}}$ Lethy Krishnan Jagadamma, (D) $t^{\mathrm{b}}$ Najwa Mousa Latif, ${ }^{a}$ \\ Arvydas Ruseckas, ${ }^{b}$ Ifor D. W. Samuel (D) *b and Graeme Cooke (D)*a
}

\begin{abstract}
The study of small donor molecules as the active component of organic solar cells continues to attract considerable attention due to the range of advantages these molecules have over their polymeric counterparts. Here we report the synthesis and solar cell fabrication of three BODIPY small molecule donors. Two of the dyes feature triphenylamine and phenothiazine as donor units attached to the meso and $\alpha$-positions of the BODIPY core (TPA-PTZ-DBP and PTZ-TPA-BDP). Additionally, we have synthesised a push-pull derivative featuring phenothiazine moieties in the $\alpha$-positions and a nitrobenzene in the meso-position (N-TPA-BDP) in order to investigate what effect this type of functionalisation has on the photovoltaic properties compared to the other dyes. The optoelectronic properties were investigated and the dyes showed broad absorption in the near-infrared with high extinction coefficients. Electrochemical measurements indicated good reversibility for the dyes redox processes. In contrast with the all-donor functionalised systems, N-TPA-BDP demonstrated extensive HOMO-LUMO overlap by DFT. The dyes were investigated as donor molecules in bulk heterojunction solar cells along with $\mathrm{PC}_{71} \mathrm{BM}$, and under optimal donor to acceptor ratio PTZ-TPA-BDP showed the highest PCE of $1.62 \%$. N-PTZ-BDP:PC ${ }_{71} B M$ was the only blend to further improve upon thermal annealing reaching the highest conversion efficiency among the dyes of $1.71 \%$. A morphology comprised of finely mixed donor and acceptor components is observed for $\mathrm{BHJ}$ blends of each of the three donors at their optimum fullerene content. Upon thermal annealing, these morphological features remain mostly the same for PTZ-TPA-BDP:PC ${ }_{71} B M$ and TPA-PTZ-DBP:PC ${ }_{71} B M$ blends whereas for N-PTZ$B D P: P C_{71} B M$ the domains show a larger size. These dyes show that phenothiazine functionalisation of BODIPY is useful for solar cells because it gives strong and broad absorption extending to the near infrared and materials with reversible redox properties - both of which are desirable for organic solar cells.
\end{abstract}

\section{Introduction}

Organic electronic materials have undergone considerable development and possess several attractive features for applications such as transistors, ${ }^{1}$ light emitting diodes ${ }^{2}$ and solar cells. $^{3,4}$ Organic photovoltaic (OPV) materials have attracted considerable attention due to their low cost, flexibility, high optical absorption coefficient, and simple fabrication. ${ }^{5,6}$ To obtain high performance and good stability, OPV materials need to have broad absorption, enable efficient charge generation and extraction whilst also having reversible redox

${ }^{a}$ School of Chemistry, University of Glasgow, Joseph Black Building, Glasgow, G12 8QQ, UK. E-mail: Graeme.Cooke@glasgow.ac.uk

${ }^{b}$ Organic Semiconductor Centre, SUPA, School of Physics and Astronomy, University of St. Andrews, St. Andrews, Fife, KY16 9SS, UK. E-mail: idws@st-andrews.ac.uk

$\dagger$ Electronic supplementary information (ESI) available. See DOI: 10.1039/c9ra01750j

\$ These authors contributed equally. processes. $^{7}$ Enormous effort has been directed towards device engineering and optimization of the chemical structure of active materials which has resulted in ever increasing efficiency of both polymer and small molecule solar cells. ${ }^{\mathbf{8 - 1 0}}$ Bulk heterojunction (BHJ) solar cells are fabricated from a blend of an electron donor (D) and an electron acceptor (A), ${ }^{11}$ and consist typically of a low bandgap polymer or small molecule. One of the many advantages of organic solar cells is that for many materials the devices can be fabricated using solutionprocessing techniques, which favour large-scale production, and have led to organic solar cells achieving power conversion efficiencies (PCE) $>10 \% .^{4,12,13}$ Small molecules continue to be very attractive candidates for organic solar cells as they can be typically synthesized in large scale with reproducible and well established protocols and are becoming competitive with their macromolecular brethren in terms of power conversion efficiencies. $^{5}$

The design of active materials in OPV research is an ongoing challenge in order to produce small molecules that possess 
strong optical absorption characteristics and appropriate orbital offset to favour light harvesting, exciton diffusion and promote high charge carrier mobility. ${ }^{12,14}$ Borondipyrromethene (BODIPY) dyes have emerged in recent years as interesting dyes for OPVs because they possess many of these properties. In addition, BODIPYs usually possess good chemical, photochemical and thermal stability, and often feature deep HOMO energy levels which lead to a high open circuit voltage $\left(V_{\mathrm{oc}}\right) \cdot{ }^{15,16}$ Several strategies have been taken to modify the BODIPY core and tune the properties in the desired direction. ${ }^{\mathbf{1 4 - 2 4}}$ Diverse molecular structures have been investigated by attaching donor moieties to different positions of the BODIPY core giving molecules with near IR absorption, high molecular extinction coefficient $(\varepsilon),{ }^{\mathbf{1 5 , 1 9 , 2 2 , 2 5 - 2 7}}$ near-planar molecular structure, ${ }^{14,17,28}$ efficient charge transport and good quality film formation, ${ }^{16,17,19,28}$ together with favourable power conversion efficiencies (PCEs). ${ }^{29}$ However, despite the remarkable photophysical properties and the promising results reported so far, ${ }^{29-31}$ understanding the role functional units attached to the BODIPY core play in determining their optoelectronic and photovoltaic properties remains an important goal in order to understand the best approach to combine donor and acceptor units within these dyes to produce different BODIPY based BHJ solar cells.

The incorporation of donor moieties on the 3,5-positions $(\alpha)$ of the BODIPY core appears to be the preferred approach to avoid highly twisted structures. ${ }^{\mathbf{1 4 1 9 - 2 2}}$ In fact, one of the best performing BODIPY dyes possessing a highly planar molecular structure is functionalized with vinyl-thiophene units attached to these positions. ${ }^{\mathbf{1 4}}$ On the other hand, Mao et al. recently indicated that phenothiazine (PTZ) donor moieties communicate adequately with the BODIPY core through the 2,6-positions which leads to some of the best performing BODIPY-based dye sensitized solar cells, ${ }^{32,33}$ presumably due to the electron donating ability and near-planar butterfly conformation of the PTZ unit. ${ }^{34}$ Interestingly, Liao et al. recently used this moiety to fabricate a 2,6-linked dimer for $\mathrm{BHJ}$ solar cells that achieved a $3.33 \%$ PCE. ${ }^{17}$ Therefore, incorporation of these moieties in the $\alpha$-positions is attractive as $\alpha$-substituted BODIPYs possess some of the most attractive properties from this family of dyes for OPVs (including near-IR absorption and high absorptivity). ${ }^{\mathbf{1 6 , 3 5}}$
In the present work, we report the synthesis and characterization of three new BODIPY dyes functionalized in the meso and $\alpha$ positions for application as donor material in BHJ solar cells. We have investigated the effect of adding three donor units [phenothiazine (PTZ) and triphenylamine (TPA)] to the meso and $\alpha$-positions (abbreviated from hereafter as PTZ-TPA-BDP and TPA-PTZ-BDP) and in the case of N-PTZ-BDP the addition of an electron accepting nitrobenzene unit to the meso-position of the BODIPY core has on the optical, electronic and $\mathrm{BHJ}$ solar cell device characteristics (Fig. 1).

\section{Experimental section}

\section{General synthesis}

All the reagents were purchased from Sigma Aldrich ${ }^{\circledR}$, Fluorochem $\AA$, TCI $\AA$, Alfa Aesar ${ }^{\circledR}$, Acros ${ }^{\circledR}$ or Fisher Scientific $\AA$ and used as received. Column chromatography was carried out using silica gel (Sigma-Aldrich) 40-63 $\mu \mathrm{m}$ particle size (60 Å pore size). Thin-layer chromatography (TLC) was performed using Merck silica gel 60 covered aluminium plates F254. Dry solvents were obtained from Innovative Technology inc. Pure Solv 400-5MD solvent purification system (activated alumina columns) or Sigma Aldrich ${ }^{\circledR}$. Melting points (Mp) were recorded on a SMP10 Stuart Scientific melting point machine and are uncorrected.

NMR spectra were obtained using either a Bruker Avance III 400 or a Bruker Avance III 500 spectrometers. Mass spectra were obtained from the mass spectrometry service at the University of Glasgow. All the spectroscopic and electrochemical data were processed using the Origin Pro 8.5 software suite.

\section{Synthesis of $3^{36}$}

$10 \mathrm{H}$-Phenothiazine (1) $(5.00 \mathrm{~g}, 25.0 \mathrm{mmol})$ and potassium tertbutoxide $(3.50 \mathrm{~g}, 31.2 \mathrm{mmol})$ were dissolved in dry THF $(30 \mathrm{~mL})$ and the solution was stirred under an argon atmosphere for $1 \mathrm{~h}$. 2-Ethylhexyl bromide (2) (4.5 mL, $4.9 \mathrm{~g}, 25 \mathrm{mmol}$ ) was added dropwise and the reaction mixture was stirred under reflux for $24 \mathrm{~h}$. The mixture was cooled to room temperature, washed with brine $(100 \mathrm{~mL})$, extracted with DCM $(2 \times 100 \mathrm{~mL})$, dried over $\mathrm{MgSO}_{4}$ and filtered. After evaporation of the solvent under reduced pressure, flash column chromatography was
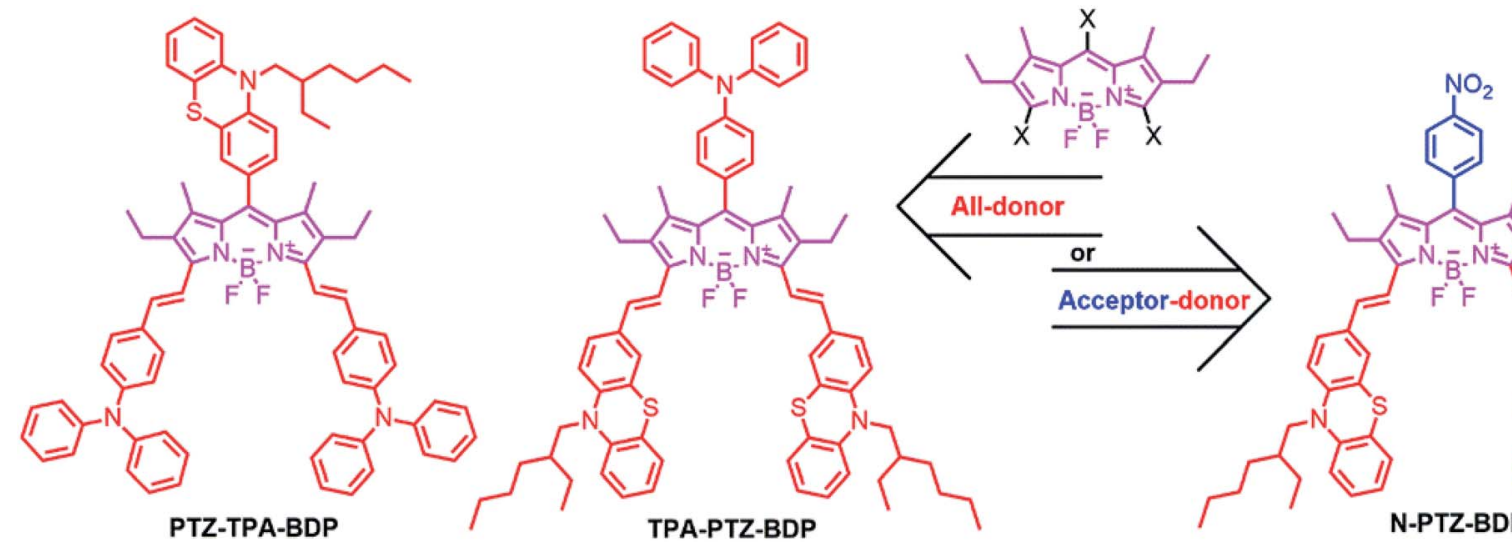

Fig. 1 Chemical structures of the BODIPY derivatives used in this study. 
performed over silica gel using petroleum ether as eluent to yield the desired product 3 as a colourless oil $(6.53 \mathrm{~g}, 83 \%) .{ }^{1} \mathrm{H}$ NMR (400 MHz, $\mathrm{CDCl}_{3}$ ) $\delta$ 7.21-7.12 (m, 4H), $6.91(\mathrm{~m}, 4 \mathrm{H}), 3.75$ $(\mathrm{d}, J=7.1 \mathrm{~Hz}, 2 \mathrm{H}), 2.04-1.88(\mathrm{~m}, 1 \mathrm{H}), 1.59-1.35$ (m, 4H), 1.33$1.20(\mathrm{~m}, 4 \mathrm{H}), 0.92-0.85(\mathrm{~m}, 6 \mathrm{H}) ;{ }^{13} \mathrm{C}$ NMR (101 MHz, $\mathrm{CD}_{3^{-}}$ $\left.\mathrm{COCD}_{3}\right) \delta 146.9,128.3,128.2,126.5,123.4,117.2,51.6,36.9$, $31.4,29.3,24.7,23.8,14.4,11.0 ; \mathrm{m} / z\left(\mathrm{ESI}^{+}\right) 311.1702\left[\mathrm{M}^{+}\right]$ $\left(\mathrm{C}_{20} \mathrm{H}_{25} \mathrm{NS}\right.$ requires 311.1708$)$.

\section{Synthesis of $4^{36}$}

$\mathrm{POCl}_{3}(20.0 \mathrm{~mL}, 32.8 \mathrm{~g}, 0.21 \mathrm{~mol})$ was added slowly into DMF $(16.0 \mathrm{~mL}, 15.1 \mathrm{~g}, 0.20 \mathrm{~mol})$ at $0{ }^{\circ} \mathrm{C}$ under an argon atmosphere. The reaction mixture was stirred for $1 \mathrm{~h}$. The mixture was slowly added to a solution of compound $3(6.50 \mathrm{~g}, 20.9 \mathrm{mmol})$ in 1,2dichloroethane $(100 \mathrm{~mL})$ at $0{ }^{\circ} \mathrm{C}$. After complete addition, the mixture was stirred at $90{ }^{\circ} \mathrm{C}$ for $24 \mathrm{~h}$ under an argon atmosphere. The reaction mixture was cooled to room temperature, neutralized with a saturated solution of $\mathrm{K}_{2} \mathrm{CO}_{3}(100 \mathrm{~mL})$ and extracted with DCM $(3 \times 100 \mathrm{~mL})$. The organic layer was washed with water $(300 \mathrm{~mL})$, dried over $\mathrm{MgSO}_{4}$ and filtered. After evaporation of the solvent under reduced pressure, flash column chromatography was performed over silica gel (petroleum ether:DCM; $8: 2$ ) to yield the desired product 4 as a yellow oil (6.48 g, 91\%). ${ }^{1} \mathrm{H}$ NMR $\left(400 \mathrm{MHz} \mathrm{CDCl}_{3}\right) \delta 9.80(\mathrm{~s}$, $1 \mathrm{H}), 7.69-7.59(\mathrm{~m}, 2 \mathrm{H}), 7.17(\mathrm{~m}, 2 \mathrm{H}), 7.03-6.87(\mathrm{~m}, 3 \mathrm{H}), 3.85-$ $3.76(\mathrm{~m}, 2 \mathrm{H}), 2.02-1.84(\mathrm{~m}, 1 \mathrm{H}), 1.51-1.33(\mathrm{~m}, 4 \mathrm{H}), 1.32-1.17$ $(\mathrm{m}, 4 \mathrm{H}), 0.86(\mathrm{~m}, 6 \mathrm{H}) ;{ }^{13} \mathrm{C} \mathrm{NMR}\left(101 \mathrm{MHz}, \mathrm{CDCl}_{3}\right) \delta$ 190.2, 151.6, $144.1,131.2$, 129.9, 128.8, 127.9, 127.6, 126.3, 125.0, 123.7, 116.7, 115.6, 51.5, 36.1, 30.7, 28.6, 24.0, 23.1, 14.1, 10.5; m/z $\left(\mathrm{ESI}^{+}\right) 362.1549\left[\mathrm{M}+\mathrm{Na}^{+}\right]\left(\mathrm{C}_{21} \mathrm{H}_{25} \mathrm{NOSNa}\right.$ requires 362.1555).

\section{Synthesis of 8}

2,4-Dimethy-3-ethyl pyrrole (5) (1.1 mL, $8.1 \mathrm{mmol})$ and compound $4(1.38 \mathrm{~g}, 4.06 \mathrm{mmol})$ were dissolved in argon-degassed DCM (300 $\mathrm{mL})$. Three drops of trifluoroacetic acid were added and the mixture was stirred for $24 \mathrm{~h}$ at room temperature. During this time the solution changed from pale yellow to a deep red colour. $p$-Chloranil ( $1.00 \mathrm{~g}, 4.06 \mathrm{mmol}$ ) was then added to the mixture at $0{ }^{\circ} \mathrm{C}$ and the reaction was allowed to stir for $3 \mathrm{~h}$. $\mathrm{N}, \mathrm{N}$-diisopropylethylamine $(8.0 \mathrm{~mL}, 45 \mathrm{mmol})$ was added to the mixture dropwise at room temperature over a period of $5 \mathrm{~min}$, and the solution was stirred for $30 \mathrm{~min}$. Subsequently, $\mathrm{BF}_{3} \cdot \mathrm{OEt}_{2}(8.0, \mathrm{~mL}$, $64.8 \mathrm{mmol}$ ) was added dropwise at $0{ }^{\circ} \mathrm{C}$ over a period of $10 \mathrm{~min}$, and the mixture was stirred overnight at room temperature. The reaction mixture was washed with water $(50 \mathrm{~mL})$, extracted with DCM $(2 \times 50 \mathrm{~mL})$, dried over $\mathrm{MgSO}_{4}$ and filtered. After evaporation of the solvent under reduced pressure, flash column chromatography was performed over silica gel (DCM : petroleum ether; $4: 1)$ to yield the desired product 8 as a red solid $(1.58 \mathrm{~g}$, 63\%). Mp: $147-149{ }^{\circ} \mathrm{C} ;{ }^{1} \mathrm{H}$ NMR (400 MHz, $\left.\mathrm{CDCl}_{3}\right) \delta 7.23-7.10(\mathrm{~m}$, 2H), 7.04-6.99 (m, 2H), 6.98-6.89 (m, 3H), 3.78 (d, $J=7.2 \mathrm{~Hz}, 2 \mathrm{H})$, $2.52(\mathrm{~s}, 6 \mathrm{H}), 2.30(\mathrm{q}, J=7.5 \mathrm{~Hz}, 4 \mathrm{H}), 2.03-1.90(\mathrm{~m}, 1 \mathrm{H}), 1.49-1.37$ $(\mathrm{m}, 4 \mathrm{H}), 1.40(\mathrm{~s}, 6 \mathrm{H}), 1.27(\mathrm{q}, J=7.6,4.6 \mathrm{~Hz}, 4 \mathrm{H}), 0.98(\mathrm{t}, J=$ $7.6 \mathrm{~Hz}, 6 \mathrm{H}), 0.88-0.84(\mathrm{~m}, 6 \mathrm{H}) ;{ }^{13} \mathrm{C} \mathrm{NMR}\left(101 \mathrm{MHz}, \mathrm{CDCl}_{3}\right)$ $\delta$ 153.7, 145.9, 145.7, 139.5, 138.4, 132.8, 131.1, 129.4, 127.6, $127.4,127.3$, 127.1, 126.9, 125.2, 122.8, 116.5, 116.1, 51.4, 35.9,
$30.7,28.7,24.0,23.1,17.2,14.7,14.1,12.6,12.2,12.1,10.6 ; \mathrm{m} / \mathrm{z}$ $\left(\mathrm{FAB}^{+}\right) 613.3469\left[\mathrm{M}^{+}\right]\left(\mathrm{C}_{37} \mathrm{H}_{46}{ }^{11} \mathrm{BF}_{2} \mathrm{~N}_{3} \mathrm{~S}\right.$ requires 613.3479).

\section{Synthesis of TPA-PTZ-BDP}

Compounds 7 (0.80 g, $1.46 \mathrm{mmol})$ and 4 (2.48 g, $7.31 \mathrm{mmol})$ were dissolved in dry toluene $(30 \mathrm{~mL})$ containing activated molecular sieves $(80 \mathrm{mg}, 4 \AA$ A $)$. Acetic acid $(6.4 \mathrm{~mL})$ and piperidine $(6.4 \mathrm{~mL})$ were added into the solution and the mixture was stirred under an argon atmosphere under reflux until consumption of the starting material was confirmed by TLC. The mixture was cooled to room temperature and the solvent was evaporated under reduced pressure. Subsequently, the reaction mixture was washed with brine $(50 \mathrm{~mL})$, extracted with DCM $(3 \times 50 \mathrm{~mL})$, dried over $\mathrm{MgSO}_{4}$ and filtered. After evaporation of the solvent under reduced pressure, flash column chromatography was performed over silica gel $\left(\mathrm{CHCl}_{3}-\right.$ : petroleum ether; $1: 1)$ to yield the desired product TPA-PTZBDP as a dark green solid (0.143 g, 8\%). Mp: 245-247 ${ }^{\circ} \mathrm{C} ;{ }^{1} \mathrm{H}$ NMR $\left(400 \mathrm{MHz}, \mathrm{CDCl}_{3}\right) \delta 7.65(\mathrm{~d}, J=16.7 \mathrm{~Hz}, 2 \mathrm{H}), 7.48(\mathrm{dd}, J=$ $8.5,1.9 \mathrm{~Hz}, 2 \mathrm{H}), 7.37$ (d, J=1.9 Hz, 2H), 7.34-7.28 (m, 4H), 7.20$7.13(\mathrm{~m}, 14 \mathrm{H}), 7.10-7.04(\mathrm{~m}, 2 \mathrm{H}), 6.97-6.87(\mathrm{~m}, 6 \mathrm{H}), 3.78(\mathrm{~d}, J=$ $7.1 \mathrm{~Hz}, 4 \mathrm{H}), 2.62$ (q, $J=7.4 \mathrm{~Hz}, 4 \mathrm{H}), 2.04-1.91(\mathrm{~m}, 2 \mathrm{H}), 1.54(\mathrm{~s}$, $6 \mathrm{H}), 1.52-1.36(\mathrm{~m}, 8 \mathrm{H}), 1.33-1.25(\mathrm{~m}, 8 \mathrm{H}), 1.17(\mathrm{t}, J=7.5 \mathrm{~Hz}$, $6 \mathrm{H}), 1.94-0.84(\mathrm{~m}, 12 \mathrm{H}) ;{ }^{13} \mathrm{C} \mathrm{NMR}\left(101 \mathrm{MHz}, \mathrm{CDCl}_{3}\right) \delta 150.2$, $148.5,147.5,146.1,145.5,138.7,138.0,134.7,133.8,133.5$, $132.1,129.7,129.7,129.6,127.7,127.2$, 126.6, 126.4, 126.1, 125.4, 124.7, 123.6, 123.5, 122.7, 118.4, 116.1, 116.0, 51.3, 36.1, $30.8,28.7,24.1,23.2,18.6,14.2,14.1,11.8,10.6 ; \mathrm{m} / z\left(\mathrm{FAB}^{+}\right)$ $1189.6061\left[\mathrm{M}^{+}\right]\left(\mathrm{C}_{77} \mathrm{H}_{82}{ }^{11} \mathrm{BF}_{2} \mathrm{~N}_{5} \mathrm{~S}_{2}\right.$ requires 1189.6078).

\section{Synthesis of PTZ-TPA-BDP}

Compounds 8 (0.10 g, $0.16 \mathrm{mmol})$ and $6(0.22 \mathrm{~g}, 0.82 \mathrm{mmol})$ were dissolved in dry toluene $(15 \mathrm{~mL})$ containing activated molecular sieves $(10 \mathrm{mg}, 4 \AA$ A $)$. Acetic acid $(0.8 \mathrm{~mL})$ and piperidine $(0.8 \mathrm{~mL})$ were added into the solution and the mixture was stirred under an argon atmosphere under reflux until consumption of the starting material was confirmed by TLC. The mixture was cooled to room temperature and the solvent was evaporated under reduced pressure. Subsequently, the reaction mixture was washed with brine $(50 \mathrm{~mL})$, extracted with DCM $(3 \times 50 \mathrm{~mL})$, dried over $\mathrm{MgSO}_{4}$ and filtered. After evaporation of the solvent under reduced pressure, flash column chromatography was performed over silica gel $\left(\mathrm{CHCl}_{3}-\right.$ : petroleum ether; $1: 1)$ to yield the desired product PTZ-TPABDP as a dark green solid (0.040 g, 21\%). Mp: 247-249 ${ }^{\circ} \mathrm{C} ;{ }^{1} \mathrm{H}$ NMR $\left(400 \mathrm{MHz}, \mathrm{CDCl}_{3}\right) \delta 7.67(\mathrm{~d}, J=16.7 \mathrm{~Hz}, 2 \mathrm{H}), 7.48(\mathrm{~d}, J=$ $8.7 \mathrm{~Hz}, 4 \mathrm{H}), 7.33-7.26$ (m, 7H), 7.24-7.10 (m, 13H), 7.09-7.04 $(\mathrm{m}, 10 \mathrm{H}), 7.00-6.90(\mathrm{~m}, 3 \mathrm{H}), 3.80(\mathrm{~d}, J=7.1 \mathrm{~Hz}, 2 \mathrm{H}), 2.61(\mathrm{q}, J=$ $7.2 \mathrm{~Hz}, 4 \mathrm{H}), 2.03-1.94(\mathrm{~m}, 1 \mathrm{H}), 1.51-1.38$ (m, 10H), 1.31-1.26 $(\mathrm{m}, 4 \mathrm{H}), 1.16(\mathrm{t}, J=7.5 \mathrm{~Hz}, 6 \mathrm{H}), 0.92-0.86(\mathrm{~m}, 6 \mathrm{H}) ;{ }^{13} \mathrm{C} \mathrm{NMR}(101$ $\left.\mathrm{MHz}, \mathrm{CDCl}_{3}\right) \delta 150.4,148.3,147.4,146.0,145.7,138.6,136.8$, $135.3,133.8,133.4,133.3,131.6,129.8,129.4,128.4,127.7$, $127.6,127.4,127.3,125.3,124.9,123.4,123.1,122.8,118.5$, 116.5, 116.1, 51.4, 36.0, 30.8, 28.7, 24.1, 23.2, 18.5, 14.2, 12.0, 12.0, 10.7; $m / z\left(\mathrm{FAB}^{+}\right) 1123.5527\left[\mathrm{M}^{+}\right]\left(\mathrm{C}_{75} \mathrm{H}_{72}{ }^{11} \mathrm{BF}_{2} \mathrm{~N}_{5} \mathrm{~S}\right.$ requires 1123.5575). 


\section{Synthesis of N-PTZ-BDP}

Compounds 10 (0.30 g, $0.71 \mathrm{mmol})$ and 4 (1.20 g, $7.31 \mathrm{mmol})$ were dissolved in dry toluene $(20 \mathrm{~mL})$ containing activated molecular sieves (30 mg, 4 A). Acetic acid (3.5 mL) and piperidine $(3.5 \mathrm{~mL})$ were added into the solution and the mixture was stirred under an argon atmosphere under reflux until consumption of the starting material was confirmed by TLC. The mixture was cooled to room temperature and the solvent was evaporated under reduced pressure. Subsequently, the reaction mixture was washed with brine $(50 \mathrm{~mL})$, extracted with DCM $(3 \times 50 \mathrm{~mL})$, dried over $\mathrm{MgSO}_{4}$ and filtered. After evaporation of the solvent under reduced pressure, flash column chromatography was performed over silica gel $\left(\mathrm{CHCl}_{3}-\right.$ : petroleum ether; $1: 1)$ to yield the desired product N-PTZ-BDP as a dark green solid (0.211 g, 28\%). Mp: 254-256 ${ }^{\circ} \mathrm{C} ;{ }^{1} \mathrm{H}$ NMR $\left(400 \mathrm{MHz} \mathrm{CDCl}_{3}\right) \delta 8.39(\mathrm{~d}, J=8.7 \mathrm{~Hz}, 2 \mathrm{H}), 7.65(\mathrm{~d}, J=16.7 \mathrm{~Hz}$, 2H), 7.55 (d, $J=8.7 \mathrm{~Hz}, 2 \mathrm{H}), 7.49$ (dd, $J=8.5,1.9 \mathrm{~Hz}, 2 \mathrm{H}), 7.39$ $(\mathrm{d}, J=1.9 \mathrm{~Hz}, 2 \mathrm{H}), 7.25-7.12(\mathrm{~m}, 6 \mathrm{H}), 6.99-6.86(\mathrm{~m}, 6 \mathrm{H}), 3.78$ (d, $J=7.1 \mathrm{~Hz}, 4 \mathrm{H}), 2.59$ (q, $J=7.4 \mathrm{~Hz}, 4 \mathrm{H}), 2.05-1.91$ (m, 2H), 1.531.37 (m, 8H), 1.34-1.23 (m, 14H), 1.15 (t, J=7.5 Hz, 6H), 0.89 $(\mathrm{m}, J=7.3 \mathrm{~Hz}, 12 \mathrm{H}) ;{ }^{13} \mathrm{C} \mathrm{NMR}\left(101 \mathrm{MHz}, \mathrm{CDCl}_{3}\right) \delta 151.2,148.3$, $146.5,145.3,143.5,137.8,135.6,134.5,134.1,132.4,131.9$, $131.0,130.5,127.7,127.3,126.7,126.2,125.3,124.3,122.8$, 118.0, 116.1, 116.1, 51.3, 36.1, 30.8, 28.7, 24.1, 23.2, 18.5, 14.1, 14.1, 12.0, 10.6; $\mathrm{m} / z\left(\mathrm{FAB}^{+}\right) 1067.5175\left[\mathrm{M}^{+}\right]\left(\mathrm{C}_{65} \mathrm{H}_{72}{ }^{11} \mathrm{BF}_{2} \mathrm{~N}_{5} \mathrm{O}_{2} \mathrm{~S}_{2}\right.$ requires 1067.5194$)$.

\section{UV-vis spectroscopy}

Solution UV-vis spectra were recorded using a PerkinElmer Lambda 25 UV/VIS Spectrometer. Solutions for spin-coating films were made by dissolving $10 \mathrm{mg} \mathrm{mL}^{-1}$ of the relevant BODIPY molecule in chloroform. The solution was then spincoated onto fused silica substrates at $800 \mathrm{rpm}$ for $60 \mathrm{~s}$. The UV-vis spectra of thin films were recorded with a CARY $300 \mathrm{UV}$ vis spectrophotometer and the thicknesses of the films were estimated using a Bruker Dektak 150 profilometer.

\section{Photoluminescence spectroscopy}

Photoluminescence quantum yield (PLQY) of the neat donor films was measured using an integrating sphere based measurement system (Hamamatsu, C9920-02) under nitrogen flow. ${ }^{37}$ The films were excited at a wavelength of $350 \mathrm{~nm}$. Fluorescence spectra and decay kinetics of neat films and blends with $\mathbf{P C}_{\mathbf{7 1}} \mathbf{B M}$ were measured with a Hamamatsu streak camera coupled to a spectrograph. Excitation was by $200 \mathrm{fs}$ laser pulses at $100 \mathrm{kHz}$ repetition rate from an optical parametric amplifier pumped by a Light Conversion Pharos regenerative amplifier. Films were spin-coated and measured in nitrogen atmosphere. The spectra were corrected for the wavelength-dependent sensitivity.

\section{Electrochemistry}

Solution electrochemistry (CV and SWV) was undertaken using a CH Instrument Electrochemical Workstation (CHI 440a), Austin, TX, USA. The supporting electrolyte was TBA $[\mathrm{PF}]_{6}(0.1 \mathrm{M}$ in DCM $)$ and samples were recorded at a concentration of $5 \times 10^{-4} \mathrm{M}$ and a scan rate of $0.07 \mathrm{~V} \mathrm{~s}^{-1}$. A platinum disk working electrode, a platinum wire counter electrode and a silver wire pseudo reference electrode were used for all measurements. The redox couples are referenced to ferrocene (external reference) with the $\mathrm{Fc} / \mathrm{Fc}^{+}\left(E_{1 /}\right.$ ${ }_{20 x}=0.35 \mathrm{eV}$ ) redox couple adjusted to $0.0 \mathrm{~V}$. Ionisation potentials (IP), electron affinities (EA) and $E_{\text {fund }}$ were calculated using:

$$
\begin{aligned}
& \mathrm{IP}=-\left[E_{\mathrm{ox}}+4.8\right] \mathrm{eV} \\
& \mathrm{EA}=-\left[E_{\mathrm{red}}+4.8\right] \mathrm{eV} \\
& E_{\text {fund }}=|\mathrm{IP}-\mathrm{EA}| \mathrm{eV}
\end{aligned}
$$

\section{DFT modelling}

DFT calculations were undertaken using the Gaussian 09 software suite. ${ }^{38}$ Molecular geometries were initially optimized semi-empirically (PM6) and then re-optimized by DFT B3LYP/6$31 \mathrm{G}(\mathrm{d}, \mathrm{p})$ level. The 2-ethylhexyl chains were replaced by methyl units to facilitate the convergence of the geometry optimizations. Minimum energy structures were confirmed by the absence of imaginary frequencies in the calculated IR spectra.

\section{Solar cell fabrication and characterisation}

Organic solar cells were fabricated on pre-patterned ITO-coated glass. The ITO-coated glass substrates were cleaned in detergent (sodium dodecyl sulphate), successively ultrasonicated in deionized water, acetone, and isopropyl alcohol, and exposed to oxygen in a plasma asher for 3 minutes. For each donor molecule, the photovoltaic performance optimization process was started with identifying the donor to acceptor ratio (wt\%, varying from $1: 1$ to $1: 6)$ giving the best photovoltaic performance. Then thermal annealing process (room temperature to $150{ }^{\circ} \mathrm{C}$ ) was applied to maximize the OPV device performance. The acceptor molecule used was PC $_{71} \mathbf{B M}$ (American Dye Sources, ADS71BFA) and the total concentration of the D:A blend mixture was $10 \mathrm{mg}$ $\mathrm{mL}^{-1}$ in chloroform. Donor and acceptor solutions were stirred separately for $\sim 6$ hours and then the blended mixture was stirred for another 3 hours. Devices were made by depositing PEDOT:PSS as hole injection layer having thickness $\sim 30-40 \mathrm{~nm}$. The active layer was deposited by spin - coating ( $800 \mathrm{rpm}, 60 \mathrm{~s}$ ) on glass/ITO/PEDOT:PSS substrates inside a nitrogen filled glove box. The samples were then transferred to a vacuum thermal evaporator $\left(1 \times 10^{-6}\right.$ mbar base pressure $)$ and kept under vacuum before thermally evaporating the metal contacts consisting of $\mathrm{Ca}(5 \mathrm{~nm})$ and $\mathrm{Al}(100 \mathrm{~nm})$ using a shadow mask. The active area of the device was $0.08 \mathrm{~cm}^{2}$. All the processing related to the active layer was performed inside the nitrogen glove box.

After the electrode deposition, the devices were encapsulated with a UV optical adhesive and a glass coverslip. The currentvoltage characteristics were determined under an illumination intensity of $100 \mathrm{~mW} \mathrm{~cm} \mathrm{~cm}^{-2}$ in air using an air mass 1.5 global (AM 1.5G) Sciencetech solar simulator and a Keithley 2400 source-measure unit. The illumination intensity was verified with a calibrated monosilicon detector with a KG-5 filter. The external quantum efficiency (EQE) measurements were 
performed at zero bias by illuminating the device with monochromatic light supplied from a xenon arc lamp in combination with a dual-grating monochromator.

\section{Results and discussion}

\section{Synthesis}

The synthesis of BODIPYs TPA-PTZ-BDP, PTZ-TPA-BD, and N-PTZBDP involved the multistep approach shown in Scheme 1. PTZ aldehyde $\mathbf{4}$ was synthesized following a slightly modified procedure from the literature, which consisted of alkylation of $10 \mathrm{H}$-phenothiazine followed by a Vilsmeier formylation protocol. ${ }^{36,39}$ The BODIPY derivatives were synthesized through well-established protocols, ${ }^{40-42}$ that follows a Knoevenagel type condensation as final step to obtain the target compounds with yields shown in Scheme 1.

\section{Optical properties}

The UV-vis absorption spectra of compounds TPA-PTZ-BDP, PTZ-TPA-BDP and N-PTZ-BDP were recorded in DCM solution (1

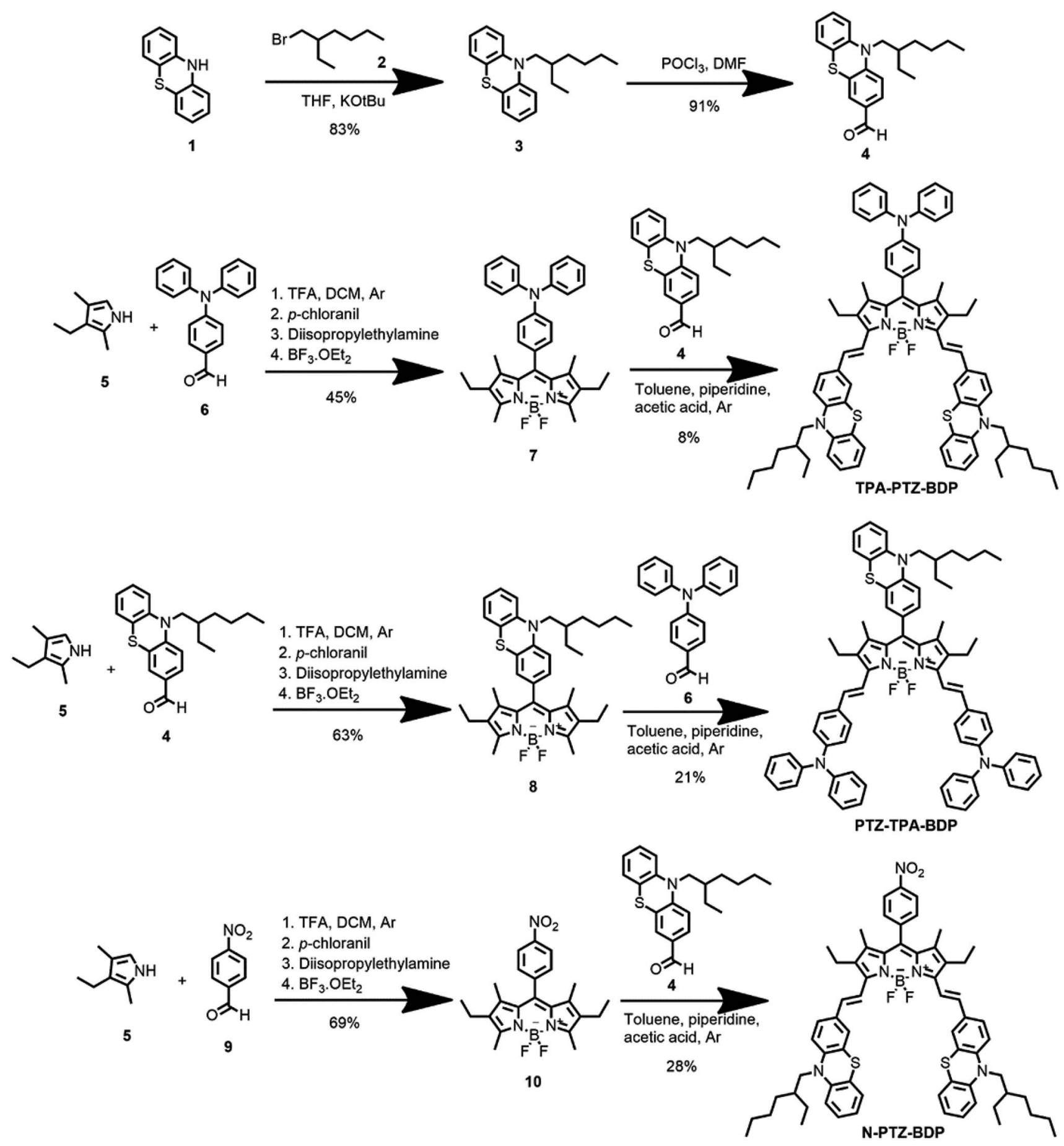


$\left.\times 10^{-5} \mathrm{M}\right)$ and as thin films on fused silica discs. The spectra are shown in Fig. 2(a) and (b) and the optical data are summarized in Table 1. As can be seen in Fig. 2(a), the three dyes (in solution) show similar values of absorption maximum $\left(\lambda_{\max }\right)$ in the visible range, $686 \mathrm{~nm}$ for TPA-PTZ-BDP, $697 \mathrm{~nm}$ for PTZ-TPA-BDP, and $702 \mathrm{~nm}$ for N-PTZ-BDP. The bands centered at around $340 \mathrm{~nm}$ are attributed to the $\pi-\pi^{*}$ transition originating from the conjugated backbone, whereas the bands centered at around $700 \mathrm{~nm}$ correspond to the $\mathrm{S}_{0}-\mathrm{S}_{1}$ transition due to the intramolecular charge transfer (ICT) between donor and acceptor moieties. The latter is expected to originate primarily from the donor moieties (located on the $\alpha$-positions) to the electron-deficient core upon photoexcitation since the (a)

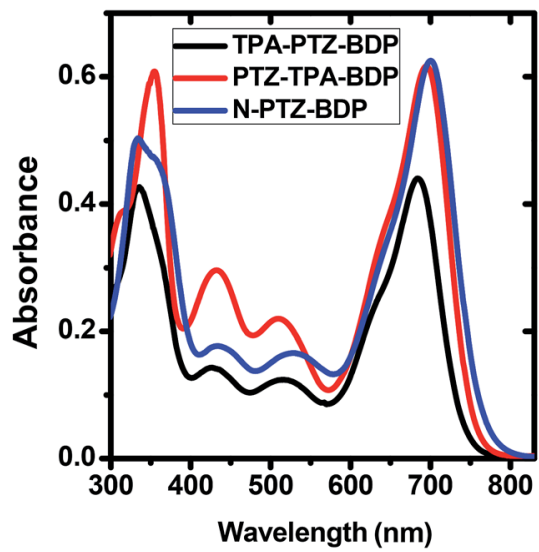

(c)

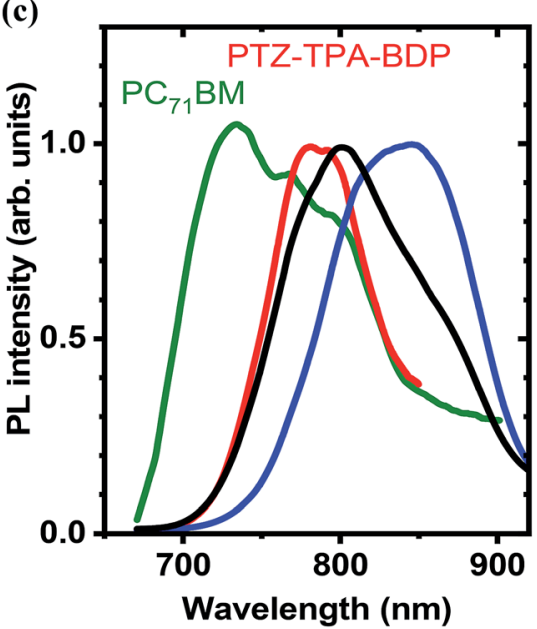

(b)

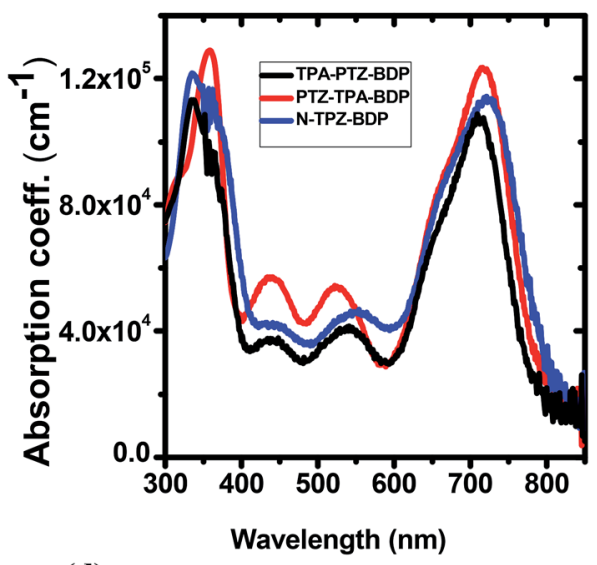

(d)

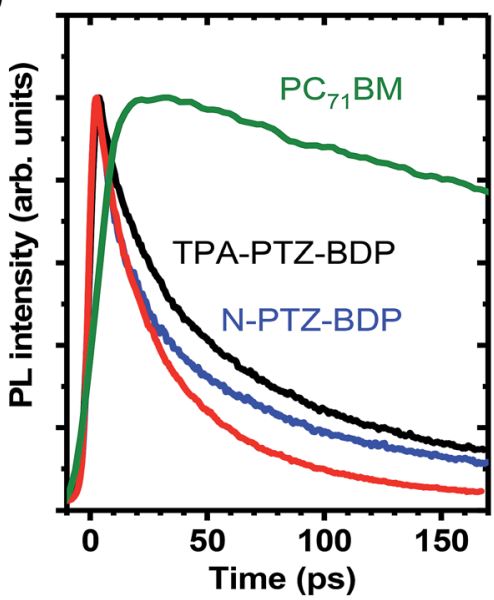

Fig. 2 (a) Absorption spectra of TPA-PTZ-BDP, PTZ-TPA-BDP and N-PTZ-BDP recorded in DCM solution ( $\left.1 \times 10^{-5} \mathrm{M}\right)$ and in (b) thin film form. (c) Normalised time-integrated fluorescence spectra of BODIPY derivatives (d) decay kinetics of the neat films recorded after excitation at $515 \mathrm{~nm}$ for $\mathrm{PC}_{71} \mathrm{BM}$ and at $660 \mathrm{~nm}$ for BODIPY derivatives. Kinetics were obtained by integrating fluorescence spectra over a $150 \mathrm{~nm}$ window for $\mathrm{BODIPY}$ derivatives and a $200 \mathrm{~nm}$ window for $\mathrm{PC}_{71} \mathrm{BM}$. Because of the weak fluorescence emission of BODIPY derivatives, the plots shown in (c) are smoothed for clarity of spectral shape.

Table 1 Summary of the optical and the electrochemical data of compounds TPA-PTZ-BDP, PTZ-TPA-BDP and N-PTZ-BDP

\begin{tabular}{|c|c|c|c|c|c|c|c|c|c|c|}
\hline Dye & $\lambda^{a}(\mathrm{~nm})$ & $\lambda_{\max }^{b}(\mathrm{~nm})$ & $\varepsilon_{\max }$ & $\begin{array}{l}\lambda_{\text {onset }} \\
(\mathrm{nm})\end{array}$ & $E_{\text {opt }}(\mathrm{eV})$ & $E_{1 / 2 \mathrm{ox}}(\mathrm{V})$ & $E_{1 / 2 \text { red }}(\mathrm{V})$ & IP $(\mathrm{eV})$ & $\mathrm{EA}(\mathrm{eV})$ & $E_{\text {fund }}(\mathrm{eV})$ \\
\hline TPA-PTZ-BDP & $\begin{array}{l}335 \\
686\end{array}$ & 711 & $4.4 \times 10^{4}$ & 754 & 1.64 & 0.23 & -1.40 & -5.03 & -3.40 & 1.63 \\
\hline PTZ-TPA-BDP & $\begin{array}{l}355 \\
697\end{array}$ & 717 & $6.2 \times 10^{4}$ & 777 & 1.59 & 0.20 & -1.38 & -5.00 & -3.42 & 1.58 \\
\hline N-PTZ-BDP & $\begin{array}{l}334 \\
702\end{array}$ & 721 & $6.3 \times 10^{4}$ & 786 & 1.57 & 0.26 & -1.30 & -5.06 & -3.50 & 1.56 \\
\hline
\end{tabular}

${ }^{a}$ Measured in DCM solution. ${ }^{b}$ Measured in thin film. 
degree of conjugation between the donor unit located at the meso-position and the core is often low. ${ }^{\mathbf{1 4 , 4 3}}$ The parent BODIPY dye molecule absorbs in the visible in the range $400-600 \mathrm{~nm}^{\mathbf{4 4 , 4 5}}$ Compounds 7, 8 and 10 show absorption maxima around 520 $\mathrm{nm}^{\mathbf{4 0}}$ [the spectra of compound $\mathbf{8}$ is given in ESI, Fig. S9†], whereas TPA-PTZ-BDP, PTZ-TPA-BDP and N-PTZ-BDP show absorption maxima at around $700 \mathrm{~nm}$. Therefore, we found that the introduction of PTZ groups in the $\alpha$-positions leads to a bathochromic effect of circa $175 \mathrm{~nm}$. Interestingly, N-PTZ-BDP shows a slight red-shifted spectrum in comparison with its counterparts. This suggests that the nitro group present in the meso-moiety increases the push-pull character of the molecule. This finding is interesting since this effect can increase the charge transfer capability of the molecule. The $\varepsilon_{\max }$ of the molecules were found to be $4.4 \times 10^{4} \mathrm{~cm}^{-1} \mathrm{M}^{-1}$ for TPA-PTZBDP, $6.2 \times 10^{4} \mathrm{~cm}^{-1} \mathrm{M}^{-1}$ for PTZ-TPA-BDP and $6.3 \times 10^{4} \mathrm{~cm}^{-1}$ $\mathbf{M}^{-1}$ for N-PTZ-BDP. The optical band-gaps $\left(E_{\text {opt }}\right)$ were estimated according to the formula $E_{\mathrm{opt}}=1240 / \lambda_{\text {onset }}$, and the values were found as 1.64, 1.59 and $1.57 \mathrm{eV}$ for TPA-PTZ-BDP, PTZ-TPA-BDP and N-PTZ-BDP, respectively (see Table 1). In summary, our molecular design strategy was successful in creating dyes with panchromatic absorption covering a large spectral range from $300 \mathrm{~nm}$ to $850 \mathrm{~nm}$ with high extinction coefficients, which is desirable for solar cell applications.

The absorption spectra of thin films of TPA-PTZ-BDP, PTZTPA-BDP and N-PTZ-BDP are shown in Fig. 2(b) and show a similar profile to those in solution. However, they show a bathochromic shift of circa 20-25 $\mathrm{nm}$ and slightly broader absorption bands which is in common with thin films of conjugated materials. ${ }^{\mathbf{4 3} 46}$ The absorption coefficient of the molecules in thin films were found to range between $1 \times 10^{5}$ $1.2 \times 10^{5} \mathrm{~cm}^{-1}$ at the peak absorption wavelength of $\sim 700 \mathrm{~nm}$. The optical bandgap estimated from the absorption onset in thin film forms are 1.58, 1.56 and $1.53 \mathrm{eV}$ for TPA-PTZ-BDP, PTZ-TPA-BDP and N-PTZ-BDP, respectively and hence close to the optimal value of band gap energy required for a single junction solar cells. ${ }^{47,48}$

The PL emission spectra of the neat donor and acceptor films are shown in Fig. 2(c). The fluorescence spectra of the three BODIPY derivatives show broad maxima around $800 \mathrm{~nm}$. The measured fluorescence of all the films was very weak and below the $1 \%$ threshold sensitivity of our PLQY measurement. The PL decay kinetics shown in Fig. 2(d) shows that the fluorescence lifetime of the BODIPY derivatives is rather short (varies between $30-60 \mathrm{ps}$ for $1 / e$ decay), which is consistent with the weak fluorescence observed.

\section{Electrochemical properties}

The electrochemical behavior of the dyes was investigated by cyclic voltammetry (CV) and square wave voltammetry (SWV). Fig. 3 shows the onset of oxidation $\left(E_{\text {ox }}\right)$ and reduction $\left(E_{\text {red }}\right)$ of the compounds, where at least one reduction and three oxidation waves can be observed for each compound. It is interesting to notice the near-reversible character of the redox waves of these dyes from the CV data displayed in Fig. 3(a). This character is important for the stability of organic solar cells since the dye needs to regenerate upon every cycle. The more positive reduction potential of N-PTZ-BDP is likely a consequence of the push-pull nature of this compound resulting from the addition of the nitrobenzene moiety, whereas the slightly lower oxidation potential of TPA-PTZ-BDP and PTZ-TPA-BDP in comparison with N-PTZ-BDP is presumably due to the donating units attached to the meso-position of the BODIPY core. The ionization potential (IP), electron affinity (EA), and consequent fundamental gap ( $\left.E_{\text {fund }}\right)$ were estimated according to the eqn (1), (2) and (3), respectively. The electrochemical data and IP and EA values are summarized in Table 1 . The IP values were obtained as $5.03 \mathrm{eV}$ for TPA-PTZ-BDP, $5.00 \mathrm{eV}$ for PTZ-TPA-BDP and $5.06 \mathrm{eV}$ for N-TPA-BDP, and the EA values were obtained as $3.40 \mathrm{eV}$ for TPA-PTZ-BDP, $3.42 \mathrm{eV}$ for PTZ-TPA-BDP and $3.50 \mathrm{eV}$ for N-TPA-BDP. Consequently, the $E_{\text {fund }}$ of the molecules were found to be 1.63, 1.58 and $1.56 \mathrm{eV}$ for TPA-PTZ-BDP, PTZ-TPABDP and N-TPA-BDP, respectively.

\section{Theoretical calculations}

In order to understand more about the electronic properties of the dyes, density functional theory (DFT) calculations at the B3LYP/6-31G(d,p) level of theory were undertaken. Firstly, as can been seen in Fig. 4, the calculations confirmed that the moieties attached to the meso-position are perpendicular to the core in all molecules and that the dihedral angle between
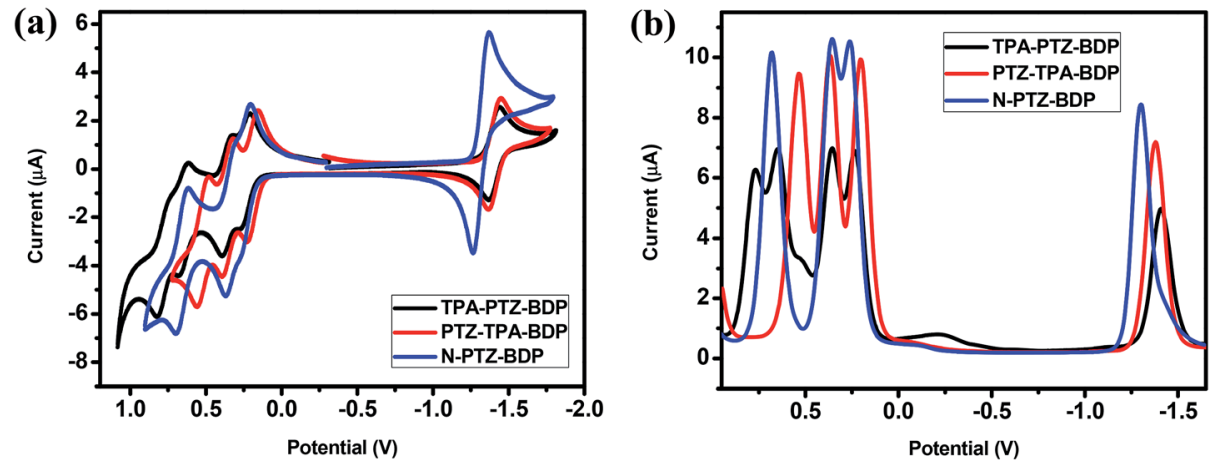

Fig. 3 (a) Cyclic voltammetry (b) square wave voltammetry traces of TPA-PTZ-BDP, PTZ-TPA-BDP and N-PTZ-BDP, recorded in DCM (5 $\times 10^{-4}$ $\mathrm{M})$, calibrated versus the ferrocene/ferrocenium $\left(\mathrm{Fc} / \mathrm{Fc}^{+}\right)$redox couple, using $\mathrm{TBA} \cdot \mathrm{PF}_{6}$ as electrolyte, a $1.6 \mathrm{~mm}$ diameter platinum working electrode, a platinum wire counter electrode and a silver wire pseudo reference electrode. 
Optimized Structure

TPA-PTZ-BDP

N-PTZ-BDP

PTZ-TPA-BDP
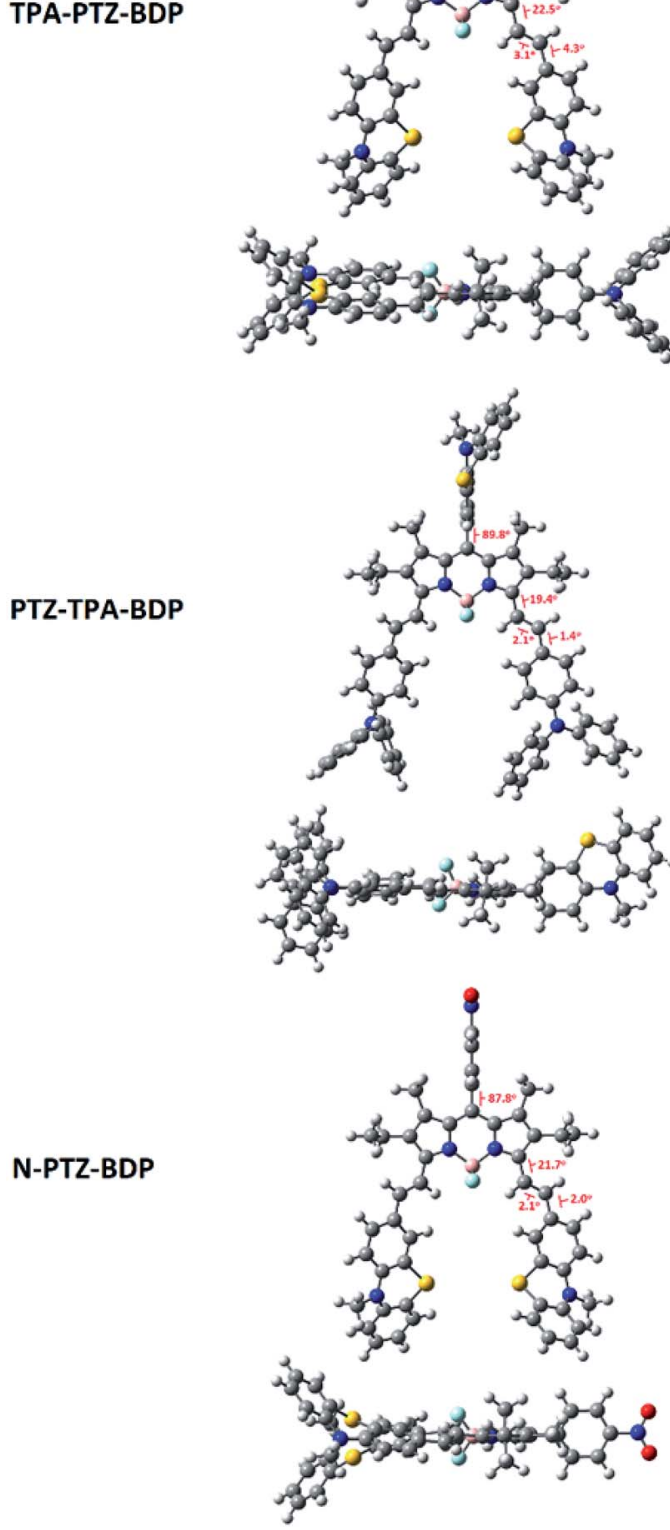

HOMO
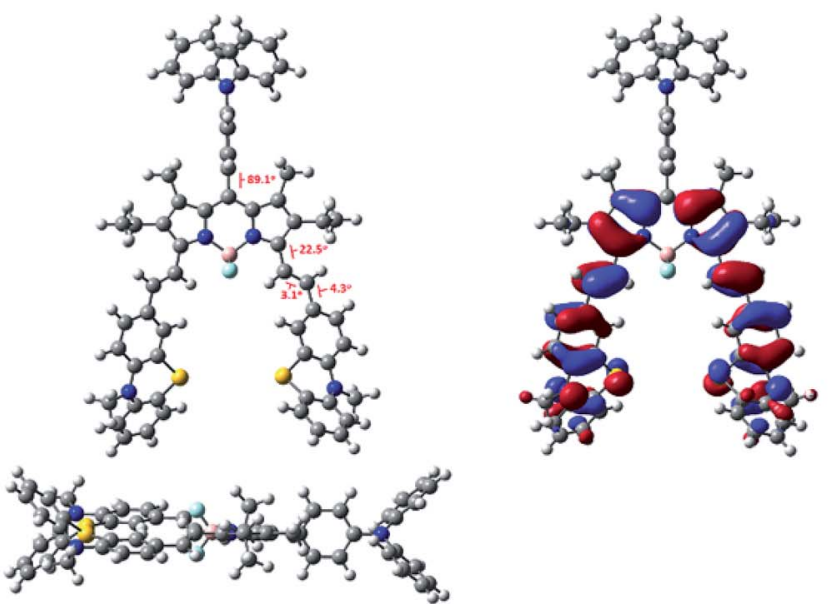

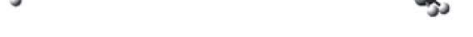

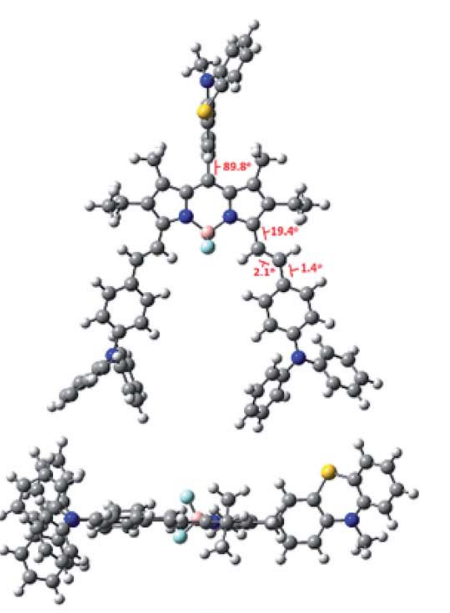
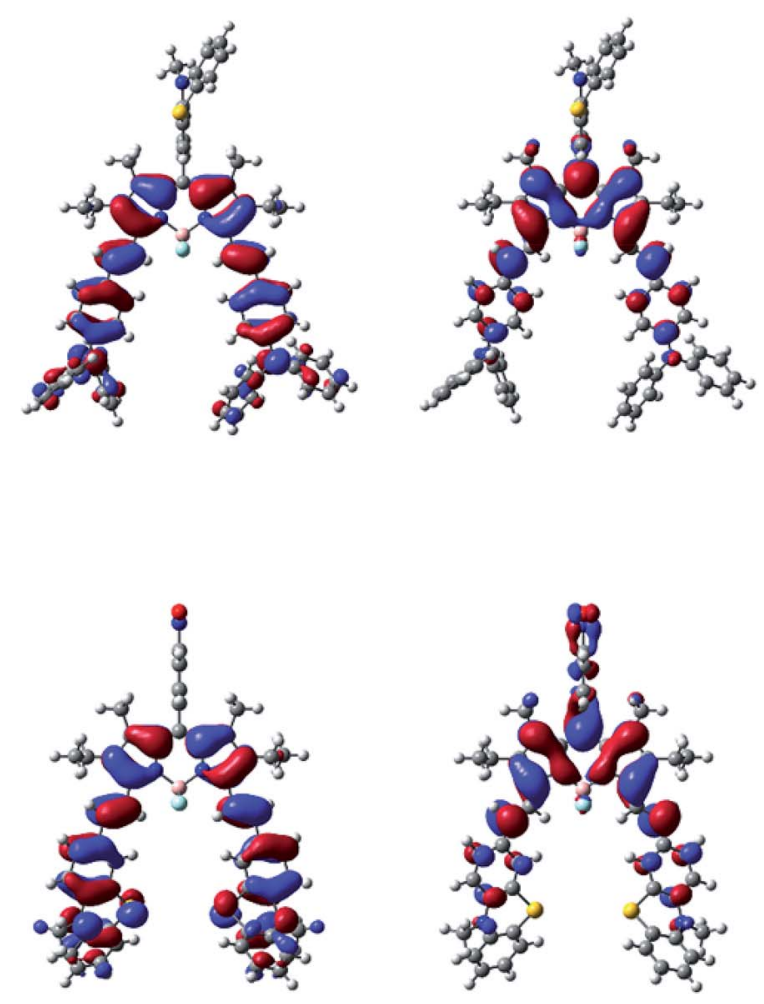

LUMO
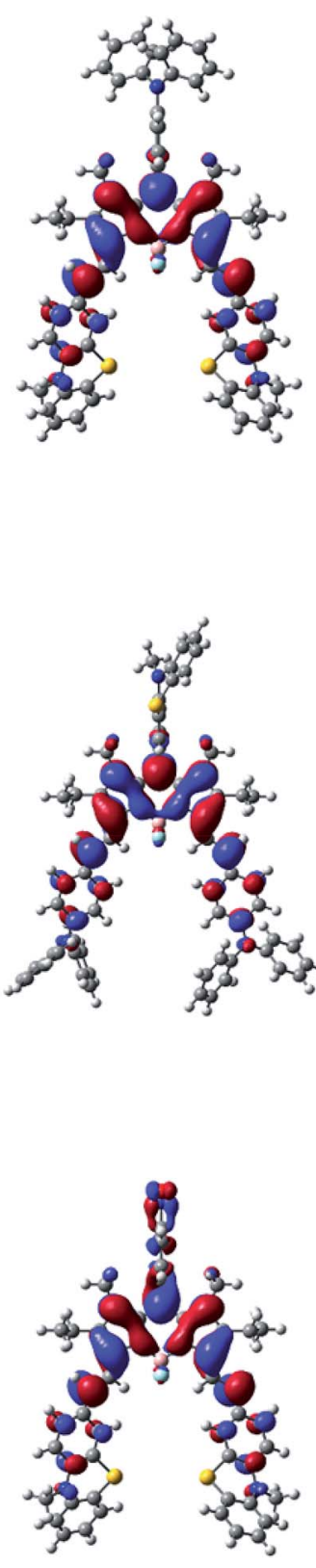

Fig. 4 Frontier orbitals (HOMO and LUMO) of compounds TPA-PTZ-BDP, PTZ-TPA-BDP and N-PTZ-BDP computed at the B3LYP level of theory and the $6-31 G(d, p)$ basis set. Molecular geometries were first optimized semi-empirically, and then re-optimized using DFT.

BODIPY and meso-units are $89.1^{\circ}$ for TPA-PTZ-BDP, $89.8^{\circ}$ for PTZ-TPA-BDP and $87.8^{\circ}$ for N-PTZ-BDP. On the other hand, a higher degree of co-planarity between the styryl donor units with the BODIPY core was observed, demonstrating that the $\pi$ conjugation is efficient through the $\alpha$-position for the three dyes. The highest occupied molecular orbital (HOMO) and the lowest unoccupied molecular orbital (LUMO) maps (see Fig. 4) clearly indicate that the HOMO is primarily located on the styryl groups extending to the BODIPY core for all three compounds, whereas the LUMO is confined to the $\pi$-framework of the BODIPY core extending only to the styryl groups in the case of TPA-PTZ-BDP and PTZ-TPA-BDP. Poor electronic communication observed between the meso-substituents and the core is usually associated with the presence of methyl groups in the positions 1- and 7-, which leads to the orthogonal arrangement. However, the LUMO of N-PTZ-BDP is interestingly located on both the nitrobenzene group attached in the meso-position and the BODIPY core extending to the styryl groups. This finding is 
interesting and corroborates with the suggestion that the nitrobenzene moiety might increase the push-pull character of the molecule. Therefore, in N-PTZ-BDP the ICT effect should be more pronounced than in the other dyes.

\section{Photovoltaic properties}

Solution processed BHJ devices were fabricated using TPA-PTZBDP, PTZ-TPA-BDP and N-PTZ-BDP as the electron donor material and $\mathbf{P C}_{\mathbf{7 1}} \mathbf{B M}$ as the acceptor material. The energy level diagram of the donor and acceptor molecules are shown in Fig. 5(a) and the device architecture (glass/ITO/PEDOT:PSS/ active layer/Ca/Al) used for fabricating OPVs is shown in Fig. 5(b). The photovoltaic performance of the dyes were evaluated systematically with careful optimization of the processing parameters such as ratio of donor to acceptor (D:A) and thermal annealing temperature.

In the case of small molecule donor based OPVs, the relative content of the donor and acceptor molecule is crucial in obtaining a homogeneously mixed $\mathrm{BHJ}$ morphology for efficient exciton harvesting and for the formation of sufficient charge transport network. ${ }^{7,49}$ The optimized weight ratio of each of the donor molecules to $\mathbf{P C}_{\mathbf{7 1}} \mathbf{B M}$ is obtained by varying it from $1: 1$ to $1: 6$ and keeping the total concentration $10 \mathrm{mg} \mathrm{mL}^{-1}$. For TPAPTZ-BDP, PTZ-TPA-BDP and N-PTZ-BDP these optimized donor to acceptor ratios are respectively $1: 6,1: 4$ and $1: 3$. Under these optimized D : A weight ratio, TPA-PTZ-BDP:PC $\mathbf{7 1}_{\mathbf{7 1}} \mathbf{B M}$ blend shows a PCE $_{\max }$ of $1.33 \%$, PTZ-TPA-BDP:PC $\mathbf{P 1}_{7 \mathbf{B M}} \mathbf{B}$ has a $\mathrm{PCE}_{\max }$ of $1.62 \%$, and N-PTZ-BDP:PC ${ }_{71} \mathbf{B M}$ shows a PCE $_{\max }$ of $1.51 \%$. The photovoltaic performance parameters, the corresponding $J-V$ characteristics and the EQE spectra of the best OPVs under optimized D : A ratio for each of the BODIPY dye molecule are shown in Fig. 6(a) and (b) and Table 2. The details of the D : A wt\% optimization details are given in ESI (Fig. S10(a)-(c), S11(a), (b) and Table S3-S5. $\dagger$ For all three BODIPY molecules, following an increase in fullerene content, the short circuit current density $\left(J_{\text {sc }}\right)$ (and hence the EQE (Fig. S11(a) and (b)†) increases systematically but with relatively smaller effects observed on open circuit voltage $\left(V_{\mathrm{oc}}\right)$ and fill factor $(\mathrm{FF})$. It has been previously reported that higher content of fullerene molecules in the oligothiophene:fullerene blends prevents the crystallization of oligothiophenes and enables the formation of a desirable carrier transport network with finer mixing of D : A components. ${ }^{\mathbf{4 9 5 0}}$ This finer mixing and better carrier transport pathways can increase the exciton harvesting and charge collection, thus accounting for the improved short circuit current density with higher $\mathbf{P C}_{\mathbf{7 1}} \mathbf{B M}$ content. Improvement in charge transport pathways can also account for the slightly improved FF with increase in fullerene content in the blend. In contrast, $V_{\mathrm{oc}}$ decreases slightly with increasing acceptor content. This can be due to the finer morphology of the $\mathrm{BHJ}$ blend with increasing content of the fullerene and/or the tail states near the quasi Fermi level due to the amorphous nature of the fullerene. ${ }^{51,52}$ It is noteworthy that although these donor molecules possess high absorption coefficients in the near infrared region (Fig. 2(b)), the $J_{\mathrm{sc}}$ values of the OPV devices are rather low $\sim 5-6 \mathrm{~mA} \mathrm{~cm}^{-2}$. This low short circuit current density could be due to unfavorable morphology of the donor-acceptor blend (vide infra) which can limit the photogenerated exciton dissociation or enhance the recombination losses of the photogenerated charge carriers. This is further discussed in detail below. Furthermore, the $V_{\mathrm{oc}}$ of these OPVs are in the range of $0.6-0.7 \mathrm{~V}$, which is due to the relatively shallow HOMO levels of these donor molecules as shown in Fig. 5(a).

To further understand the kinetics of charge pair generation, and charge transfer processes, steady state and time resolved PL measurements were carried out for the optimised blend films of BODIPY and $\mathbf{P C}_{\mathbf{7 1}} \mathbf{B M}$. Fig. 6(c) and (d) shows fluorescence spectra and kinetics which were normalised to the absorbed excitation power at the excitation wavelength, hence, charge generation efficiency in the blends can be deduced from fluorescence intensity. Photovoltaic blends of $\mathbf{P C}_{\mathbf{7 1}} \mathbf{B M}$ with BODIPY derivatives show similar spectra, albeit about 50 times weaker than the neat $\mathbf{P C}_{71} \mathbf{B M}$ film, which indicates that about $98 \%$ of excitons are quenched in the blends. Time-resolved fluorescence of the neat $\mathbf{P C}_{\mathbf{7 1}} \mathbf{B M}$ film shows a mono-exponential decay with 600 ps lifetime. The blends show about five times weaker initial intensity than the neat $\mathbf{P C}_{\mathbf{7 1}} \mathbf{B M}$ film suggesting that about $80 \%$ of charges are generated within the response function of the streak camera ( $\sim 10$ ps in this case). Rapid charge generation implies intimate mixing of two materials in the blends. Such a morphology gives fast charge pair generation at (a)

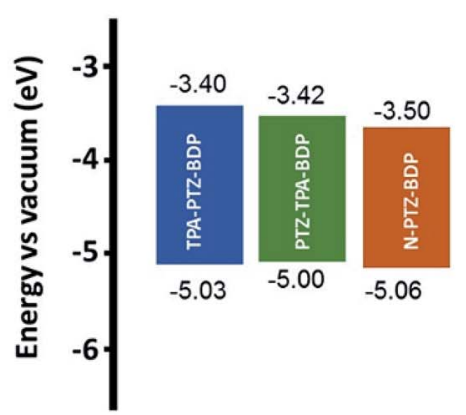

(b)

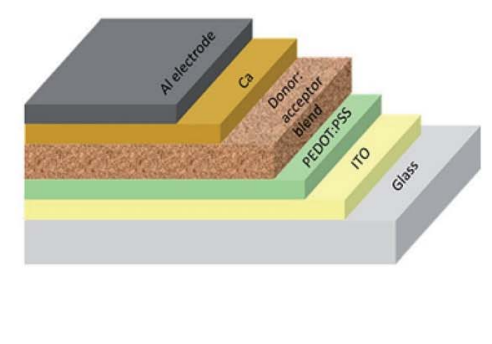

Fig. 5 (a) Energy level diagram of TPA-PTZ-BDP, PTZ-TPA-BDP, N-PTZ-BDP and PC ${ }_{71}$ BM (b) solar cell device architecture used to fabricate OPVs in this study. 
(a)
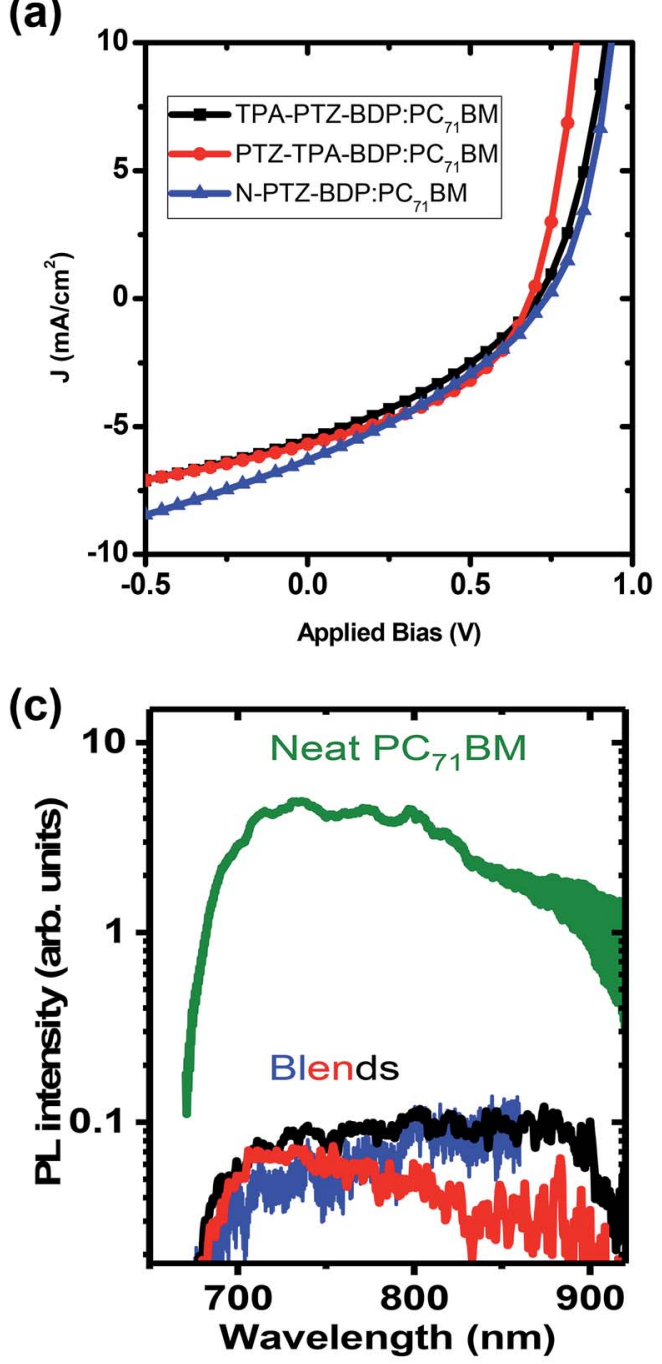

(b)

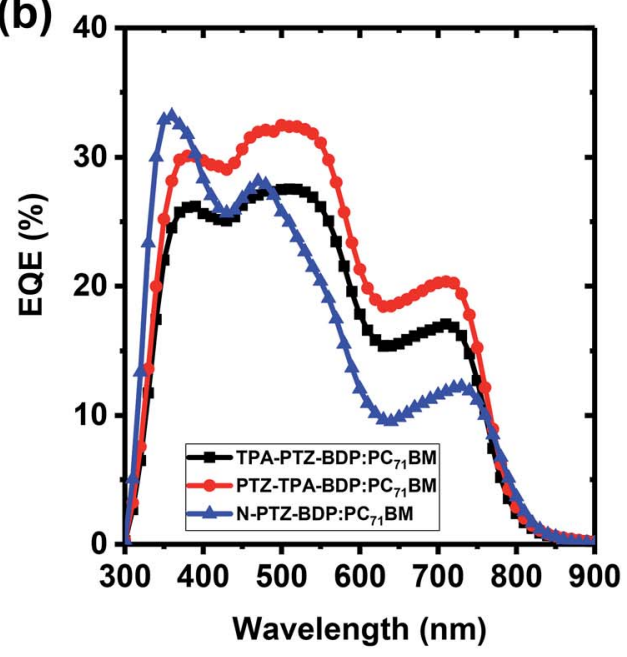

(d)

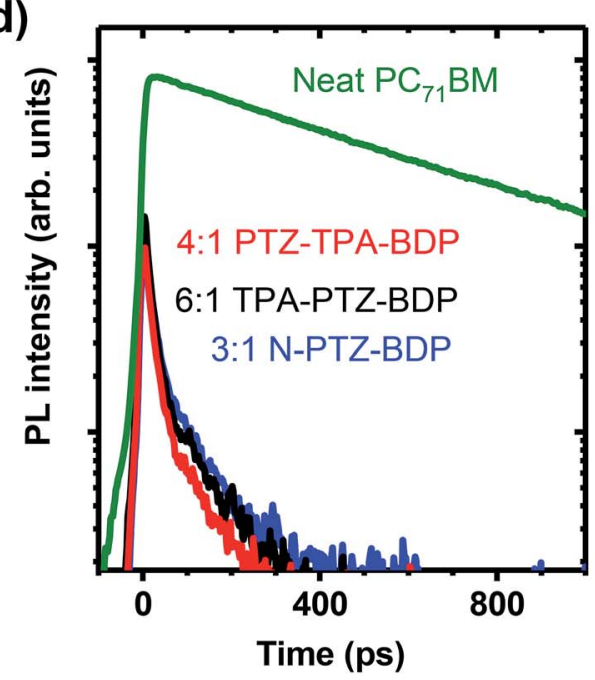

Fig. 6 (a) The J-V characteristics of the best performing OPVs for TPA-PTZ-BDP, PTZ-TPA-BDP and N-PTZ-BDP molecules for their optimized blend ratio with $P C_{71} B M$. (b) EQE spectra of the above devices. (c) Steady state fluorescence spectra and (d) decay kinetics of a neat $P C_{71} B M$ film and of the optimised photovoltaic blends containing the $\mathrm{PC}_{71} \mathrm{BM}$ : BODIPY ratio shown, recorded after excitation at $515 \mathrm{~nm}$ and normalised to the absorbed excitation power. Kinetics were obtained by integrating fluorescence spectra from $680-850 \mathrm{~nm}$. The vertical scale is logarithmic.

the interface between donor and acceptor, but enhances the recombination losses as carrier transport is interrupted by domain boundaries. ${ }^{53}$ This leads to needing a significant electric field to dissociate charge pairs and extract them, leading to the low fill factors we observe here.

Compared to the blends of TPA-PTZ-BDP and PTZ-TPA-BDP with $\mathbf{P C}_{\mathbf{7 1}} \mathbf{B M}$, the N-PTZ-BDP:PC $\mathbf{C}_{7 \mathbf{1}} \mathbf{B M}$ blend shows higher open circuit voltage, $\left(V_{\text {oc }}\right)$ as shown in Fig. 6(a) and Table 2 and that can be related to its deeper HOMO level. The EQE spectra of the TPA-PTZ-BDP:PC ${ }_{71} \mathbf{B M}$ and PTZ-TPA-BDP:PC (11 $_{\mathbf{B}} \mathbf{B M}$ follows a similar spectral profile, however N-PTZ-BDP:PC $\mathbf{7 1}_{\mathbf{7 1}} \mathbf{B M}$ blend shows a slightly different spectral shape with more absorption in the blue wavelength range. The absorption spectra of the

Table 2 The OPV performance parameters (averaged over 8 devices) for different BODIPY molecules under optimized D : A wt ratio. The \pm numbers refers to the standard deviation of each of the photovoltaic performance parameters over the 8 devices. The $J_{\text {sc }}$ estimated from EQE spectra is also included

\begin{tabular}{|c|c|c|c|c|c|c|}
\hline Donor:acceptor blend & $\begin{array}{l}\text { Donor to acceptor } \\
\text { ratio }\end{array}$ & $J_{\mathrm{sc}}\left(\mathrm{mA} \mathrm{cm}^{-2}\right)\left(J_{\mathrm{sc}}\right.$ from EQE $)$ & $V_{\mathrm{oc}}(\mathrm{V})$ & FF (\%) & PCE avg. (\%) & $\begin{array}{l}\text { PCE best } \\
(\%)\end{array}$ \\
\hline TPA-PTZ-BDP:PC ${ }_{71}$ BM & $1: 6$ & $5.09 \pm 0.36(5.22)$ & $0.687 \pm 0.015$ & $32.5 \pm 1.1$ & $1.14 \pm 0.11$ & 1.33 \\
\hline PTZ-TPA-BDP:PC ${ }_{71}$ BM & $1: 4$ & $5.70 \pm 0.11(6.20)$ & $0.672 \pm 0.008$ & $40.8 \pm 0.8$ & $1.56 \pm 0.04$ & 1.62 \\
\hline N-PTZ-BDP:PC ${ }_{71}$ BM & $1: 3$ & $5.83 \pm 0.44(4.83)$ & $0.699 \pm 0.114$ & $33.4 \pm 6.7$ & $1.33 \pm 0.14$ & 1.51 \\
\hline
\end{tabular}



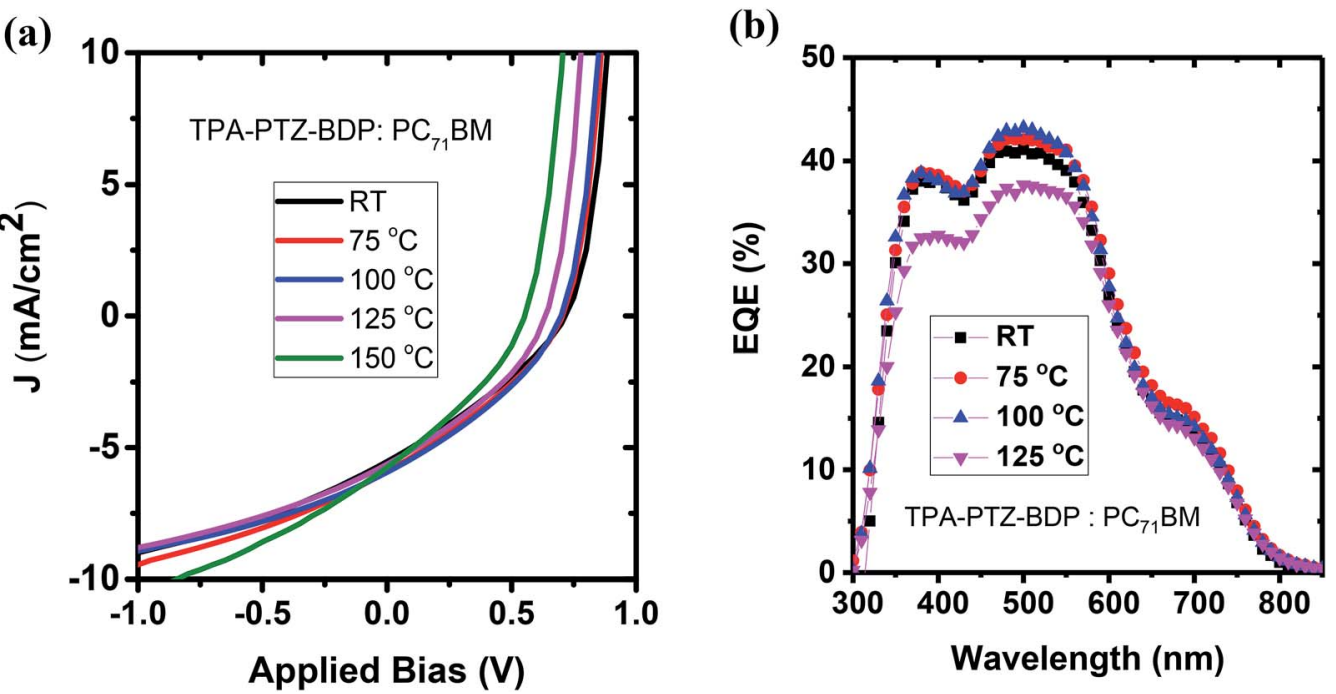

Fig. 7 (a) J-V characteristics and (b) EQE spectra of TPA-PTZ-BDP:PC ${ }_{71} B M$ as a function of different thermal annealing temperatures.

Table 3 Photovoltaic performance parameters of the TPA-PTZ-BDP:PC ${ }_{71}$ BM blend as a function of different thermal annealing temperature. The \pm numbers refers to the standard deviation of each of the photovoltaic performance parameters over the 8 devices

\begin{tabular}{|c|c|c|c|c|c|c|c|}
\hline $\begin{array}{l}\text { Anneal. temp. } \\
\left({ }^{\circ} \mathrm{C}\right)\end{array}$ & $J_{\mathrm{sc}}\left(\mathrm{mA} \mathrm{cm}{ }^{-2}\right)$ & $V_{\mathrm{oc}}(\mathrm{V})$ & $\mathrm{FF}(\%)$ & $R_{\mathrm{sh}}\left(\mathrm{ohmcm}^{2}\right)$ & $R_{\mathrm{s}}\left(\mathrm{ohmcm}^{2}\right)$ & PCE avg. (\%) & $\begin{array}{l}\text { PCE best } \\
(\%)\end{array}$ \\
\hline $\mathrm{RT}$ & $5.44 \pm 0.20$ & $0.686 \pm 0.018$ & $30.7 \pm 0.4$ & $186 \pm 5$ & $2.55 \pm 1.05$ & $1.15 \pm 0.06$ & 1.24 \\
\hline 100 & $5.83 \pm 0.11$ & $0.671 \pm 0.019$ & $33.1 \pm 0.5$ & $202 \pm 6$ & $2.78 \pm 1.16$ & $1.30 \pm 0.05$ & 1.39 \\
\hline 125 & $5.48 \pm 0.11$ & $0.622 \pm 0.011$ & $33.5 \pm 0.4$ & $197 \pm 10$ & $3.15 \pm 0.83$ & $1.15 \pm 0.04$ & 1.23 \\
\hline 150 & $5.98 \pm 0.32$ & $0.553 \pm 0.002$ & $32.5 \pm 0.8$ & $140 \pm 13$ & $2.72 \pm 0.50$ & $1.08 \pm 0.08$ & 1.19 \\
\hline
\end{tabular}

corresponding blend films of N-PTZ-BDP:PC $\mathbf{7 1}_{\mathbf{7 1}} \mathbf{B M}$ at the optimised fullerene content is given in Fig. S12. $\dagger$

To investigate whether thermal annealing process can further improve the photovoltaic properties, under each optimized D : A weight ratio, the blends were thermally annealed at different temperatures up to $150{ }^{\circ} \mathrm{C}$. In the case of TPA-PTZBDP:PC ${ }_{71} \mathbf{B M}$ blend, thermal annealing did not increase the PCE of the blend. The corresponding photovoltaic performance parameters as a function of thermal annealing are shown in Fig. 7(a) and Table 3. Similar thermal annealing also did not increase the performance of the PTZ-TPA-BDP:PC ${ }_{71} \mathbf{B M}$ blend. However for N-PTZ-BDP:PC $\mathbf{7 1}_{\mathbf{7 1}} \mathbf{B M}$ blend, thermal annealing at $70{ }^{\circ} \mathrm{C}$ improved the PCE from $1.33 \%$ to $1.71 \%$. The corresponding $J-V$ characteristics and photovoltaic performance parameters are listed in Fig. 8 and Table 4.

\section{Surface morphology by atomic force microscopy (AFM)}

To investigate how the three different BODIPY donor molecules form distinctive bulk heterojunction with $\mathbf{P C}_{\mathbf{7 1}} \mathbf{B M}$, the morphological properties of the blends were characterized using atomic force microscopy (AFM). The AFM images corresponding to the blends of TPA-PTZ-BDP:PC ${ }_{71}$ BM, PTZ-TPABDP:PC ${ }_{71} \mathbf{B M}$, and N-PTZ-BDP:PC ${ }_{71} \mathbf{B M}$ at their optimized D to A ratio are shown in Fig. 9(a)-(c). Very small domains implying fine mixing of the donor and acceptor components are seen from these AFM height images with root mean square surface roughness of less than $1 \mathrm{~nm}$ for all these blends. Thus as mentioned in the photovoltaic characterization section, at higher D: A blend ratio, (which is the optimum for three donors), this finer surface morphology can increase the photogeneration of charge carriers, but can increase the

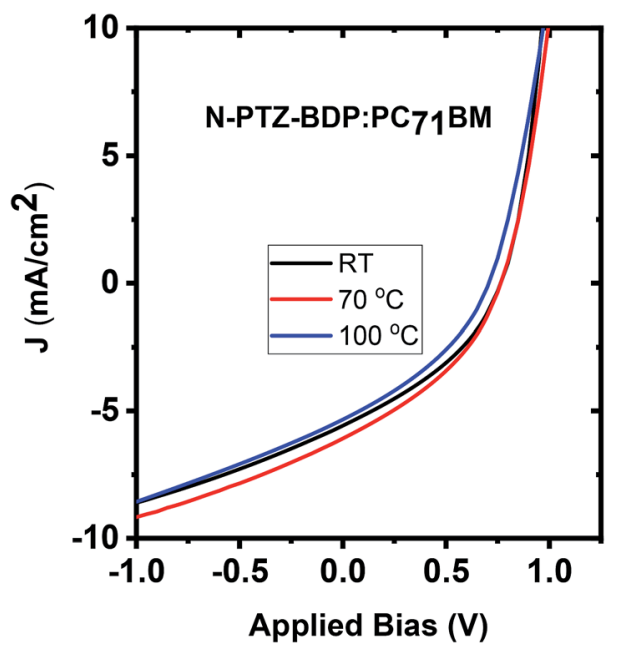

Fig. $8 \mathrm{~J}-V$ characteristics of N-PTZ-BDP:PC ${ }_{71}$ BM blend as a function of thermal annealing. 
Table 4 Photovoltaic performance parameters of N-PTZ-BDP:PC ${ }_{71} \mathrm{BM}$ as a function of thermal annealing

\begin{tabular}{|c|c|c|c|c|c|}
\hline $\begin{array}{l}\text { Thermal annealing } \\
\text { temperature }\left({ }^{\circ} \mathrm{C}\right)\end{array}$ & $J_{\mathrm{sc}}\left(\mathrm{mA} \mathrm{cm}^{-2}\right)$ & $V_{\mathrm{oc}}(\mathrm{V})$ & $\mathrm{FF}(\%)$ & PCE (\%) avg. & $\begin{array}{l}\text { PCE best } \\
(\%)\end{array}$ \\
\hline $\mathrm{RT}$ & $5.2 \pm 0.4$ & $0.762 \pm 0.006$ & $36.8 \pm 0.5$ & $1.46 \pm 0.10$ & 1.56 \\
\hline 125 & $4.76 \pm 0.54$ & $0.694 \pm 0.018$ & $33.3 \pm 2.7$ & $1.11 \pm 0.20$ & 1.34 \\
\hline
\end{tabular}
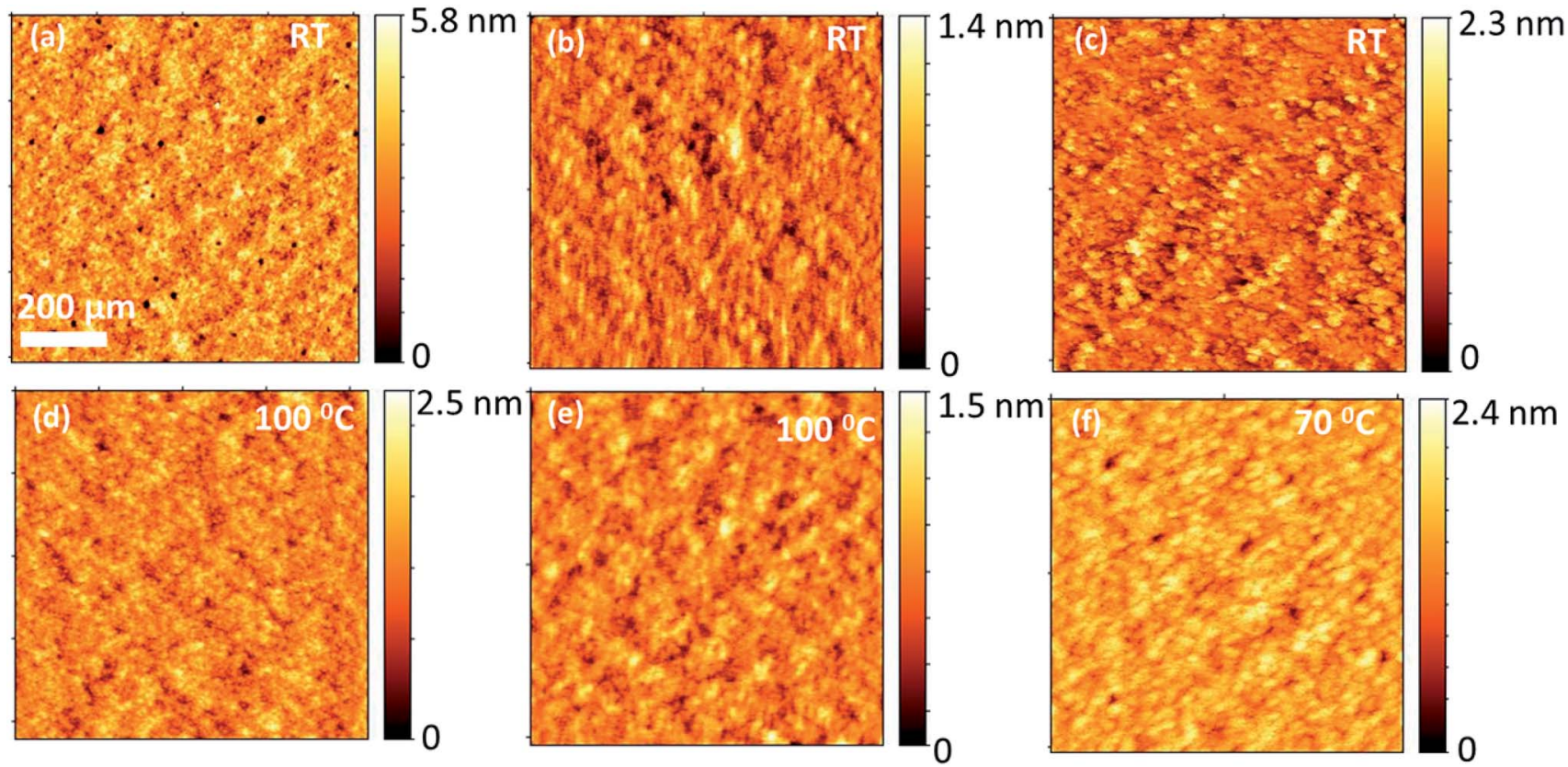

Fig. 9 Comparison of surface morphology (height images) of optimized blend ratio of each of the BODIPY donor molecules with $P C_{71} B M$ for ascast and annealed films; (a) \& (d) for PTZ:TPA-BDP:PC ${ }_{71} B M$, (b) \& (e) for TPA-PTZ-BDP:PC ${ }_{71} B M$ (c) \& (f) for N-PTZ:BDP:PC ${ }_{71} B M$.

recombination losses which is reflected in the slightly reduced open circuit voltages at higher acceptor content (Table S3-S5†). Moreover, this finer morphology of the blends, lacking bicontinuous percolative pathways to the charge collecting electrodes could be the reason for the low short circuit density and the low FF, as the possibility of charge recombination is higher for this kind of finely mixed donor and acceptor blend. ${ }^{54-56}$ Compared to TPA-PTZ-BDP:PC ${ }_{71}$ BM and PTZ-TPA-BDP:PC ${ }_{71}$ BM blends, N-PTZ-BDP:PC ${ }_{71}$ BM (Fig. 9(c)) shows slightly larger domain size for the bulk heterojunction morphology. With thermal annealing, only a marginal increase in domain size is observed for TPA-PTZ-BDP:PC ${ }_{71}$ BM and PTZ-TPA-BDP:PC ${ }_{71} \mathbf{B M}$ blends [Fig. 9(d) and (e)] whereas for N-PTZ-BDP:PC ${ }_{71}$ BM blend (Fig. 9(f)), well defined granular features and clearly larger domain size is observed. This optimized morphology may be the reason why the N-PTZ-BDP:PC $\mathbf{C}_{\mathbf{7 1}} \mathbf{B M}$ blend has slightly increased PCE with increase in thermal annealing (Table 4).

Thus our molecular engineering of BODIPY dye molecules by incorporating TPA and PTZ moieties and nitrobenzene in the meso and $\alpha$-positions resulted in favourable optoelectronic properties for photovoltaic applications, such as panchromatic absorption and reversible electrochemical properties. However, their bulk heterojunction solar cells, fabricated by blending with $\mathbf{P C}_{\mathbf{7 1}} \mathbf{B M}$ fullerenes resulted in limited photovoltaic power conversion efficiencies which could be due to the poor charge transport properties of new BODIPY dyes and suggest further work is needed to improve charge extraction.

\section{Conclusions}

Three new BODIPY donor materials featuring PTZ moieties as donor units at the $\alpha$-positions or as meso-linker, TPA-PTZ-BDP, PTZ-TPA-BDP and N-PTZ-BDP, were designed and synthesized. In N-PTZ-BDP, the introduction of an electron withdrawing motif (nitro) in the meso-substituent appears to have a beneficial effect on the mechanism of charge transfer. We found that the three dyes possess excellent panchromatic absorption covering the spectra from $300 \mathrm{~nm}$ to $850 \mathrm{~nm}$ with high extinction coefficient. However, N-PTZ-BDP showed a more extended HOMO-LUMO overlay profile revealed by DFT, and a slightly red-shifted spectra in both solution and film. The small molecules showed compatible photoelectric characteristics for the application as donor in BHJ solar cells together with $\mathbf{P C B}_{\mathbf{7 1}} \mathbf{M}$. With respect to the photovoltaic performance comparison, PTZTPA-BDP showed the highest PCE of 1.62\% under the optimized D : A ratio whereas with thermal annealing the photovoltaic 
properties of N-PTZ-BDP:PC ${ }_{71} \mathbf{B M}$ blends showed the highest PCE of $1.71 \%$. Therefore, as a result of the overall molecular composition, N-PTZ-BDP exhibited the highest conversion efficiency among the three dyes after optimization of the BHJ. This can be due to the larger length scale of phase separation and well-defined granular features observed in the $\mathrm{BHJ}$ morphology by AFM analysis. Hence, it is sensible to conclude that introducing the electronegative moiety on the meso-position had a positive effect on the absorption spectra of the BODIPY derivative extending it further towards the near infrared. Also, the near-reversible character of the redox waves of these dyes are important features that account for device stability. Finally, the findings discussed in this contribution show that the PTZ groups can make effective electron donor moieties as vinylsubstituents at the $\alpha$-position with a high degree of planarity leading to dyes that possess panchromatic absorption, and indicate that the introduction of acceptor moieties in the mesoposition is promising for high performance BODIPY-based $\mathrm{BHJ}$ solar cells.

\section{Conflicts of interest}

No conflicts to declare.

\section{Acknowledgements}

We are grateful to EPSRC for financial support (grants EP/ L012294/1 and EP/E036244/1). JMDS thanks CAPES for funding. NML thanks the Iraqi government for funding. The research data supporting this publication can be accessed at DOI: http://dx.doi.org/10.5525/gla.researchdata.666.

\section{References}

1 D. J. Gundlach, Y. Y. Lin, T. N. Jackson, S. F. Nelson and D. G. Schlom, IEEE Electron Device Lett., 1997, 18, 87-89.

2 J. Jou, S. Kumar, A. Agrawal and T. Li, J. Mater. Chem. C, 2015, 3, 2974-3002.

3 O. a. Abdulrazzaq, V. Saini, S. Bourdo, E. Dervishi and A. S. Biris, Part. Sci. Technol., 2013, 31, 427-442.

4 D. Baran, R. S. Ashraf, D. A. Hanifi, M. Abdelsamie, N. Gasparini, J. A. Röhr, S. Holliday, A. Wadsworth, S. Lockett, M. Neophytou, C. J. M. Emmott, J. Nelson, C. J. Brabec, A. Amassian, A. Salleo, T. Kirchartz, J. R. Durrant and I. Mcculloch, Nature, 2017, 16, 363-370.

5 B. Walker, C. Kim and T. Nguyen, Chem. Mater., 2011, 23, 470-482.

6 S. Holliday, R. S. Ashraf, A. Wadsworth, D. Baran, S. A. Yousaf, C. B. Nielsen, C. Tan, S. D. Dimitrov, Z. Shang, N. Gasparini, C. J. Brabec, A. Salleo, J. R. Durrant, I. Mcculloch and M. Alamoudi, Nat. Commun., 2016, 7, 1-11.

7 G. J. Hedley, A. Ruseckas and I. D. W. Samuel, Chem. Rev., 2017, 796-837.

8 Z. Wang, X. Xu, Z. Li, K. Feng, K. Li, Y. Li and Q. Peng, Adv. Electron. Mater., 2016, 2, 1-7.
9 Y. Sun, G. C. Welch, W. L. Leong, C. J. Takacs, G. C. Bazan and A. J. Heeger, Nat. Mater., 2012, 11, 44-48.

10 Y. Liu, J. Zhao, Z. Li, C. Mu, W. Ma, H. Hu, K. Jiang and H. Lin, Nat. Commun., 2014, 5, 1-8.

11 M. C. Scharber and N. S. Sariciftci, Prog. Polym. Sci., 2013, 38, 1929-1940.

12 Y. Liu, C. Chen, Z. Hong, J. Gao, H. Zhou, L. Dou, G. Li and Y. Yang, Sci. Rep., 2013, 3, 1-8.

13 B. Kan, M. Li, Q. Zhang, F. Liu, X. Wan, Y. Wang, W. Ni, G. Long, X. Yang, H. Feng, Y. Zuo, M. Zhang, F. Huang, Y. Cao, T. P. Russell and Y. Chen, J. Am. Chem. Soc., 2015, 137, 3886-3893.

14 T. Bura, N. Leclerc, S. Fall, P. Le, T. Heiser, P. Retailleau, S. Rihn, A. Mirloup and R. Ziessel, J. Am. Chem. Soc., 2012, 134, 17404-17407.

15 A. Bessette and G. S. Hanan, Chem. Soc. Rev., 2014, 43, 33423405 .

16 L. Xiao, H. Wang, K. Gao, L. Li, C. Liu, X. Peng, Y. Wong, W.-K. Wong and X. Zhu, Chem.-Asian J., 2015, 10, 1513-1518.

17 J. Liao, Y. Xu, H. Zhao, Q. Zong and Y. Fang, Org. Electron., 2017, 49, 321-333.

18 S. Niu, G. Ulrich, P. Retailleau and R. Ziessel, Org. Lett., 2011, 13, 4997-4999.

19 T. Rousseau, A. Cravino, T. Bura, G. Ulrich and J. Roncali, Chem. Commun., 2009, 1673-1675.

20 S. Kolemen, Y. Cakmak, T. Ozdemir, S. Erten-ela, M. Buyuktemiz, Y. Dede and E. U. Akkaya, Tetrahedron, 2014, 70, 6229-6234.

21 Y. Çakmak, S. Kolemen, M. Buyuktemiz, Y. Dede and S. Erten-ela, New J. Chem., 2015, 39, 4086-4092.

22 J. Liao, Y. Xu, H. Zhao, Y. Wang, W. Zhang, F. Peng, S. Xie and X. Yang, RSC Adv., 2015, 5, 86453-86462.

23 S. Y. Leblebici, L. Catane, D. E. Barclay, T. Olson, T. L. Chen and B. Ma, J. Am. Chem. Soc., 2011, 3, 4469-4474.

24 T. Bura, N. Leclerc, S. Fall, L. Patrick and R. Ziessel, Org. Lett., 2011, 13, 6030-6033.

25 H. Lin, W. Huang, Y. Chen, H. Chou, C. Hsu, J. T. Lin and H.-W. Lin, Chem. Commun., 2012, 48, 8913-8915.

26 A. Sutter, P. Retailleau, W. Huang, H. Lin and R. Ziessel, New J. Chem., 2014, 38, 1701-1710.

27 H. Klfout, A. Stewart, M. Elkhalifa and H. He, ACS Appl. Mater. Interfaces, 2017, 9, 39873-39889.

28 J. Liao, H. Zhao, Y. Xu, Z. Cai, Z. Peng, W. Zhang, W. Zhou, B. Li, Q. Zong and X. Yang, Dyes Pigm., 2016, 128, 131-140.

29 I. Bulut, Q. Huaulm, A. Mirloup, S. Fall, H. Anne, S. Mery, B. Heinrich, T. Heiser, P. Leveque and N. Leclerc, ChemSusChem, 2017, 10, 1878-1882.

30 T. Jadhav, R. Misra, S. Biswas and G. D. Sharma, Phys. Chem. Chem. Phys., 2015, 26580-26588.

31 L. Bucher, N. Desbois, E. N. Koukaras, C. H. Devillers, S. Biswas, G. D. Sharma and C. P. Gros, J. Mater. Chem. A, 2018, 6, 8449-8461.

32 M. Mao, X. Zhang, X. Fang, G. Wu, Y. Ding and X. Liu, Org. Electron., 2014, 15, 2079-2090.

33 M. Mao, X. Zhang, L. Cao, Y. Tong and G. Wu, Dyes Pigm., 2015, 117, 28-36.

34 M. Mao and Q. Song, Chem. Rec., 2016, 16, 719-733. 
35 J. C. Forgie, P. J. Skabara, I. Stibor, F. Vilela and Z. Vobecka, Chem. Mater., 2009, 21, 1784-1786.

36 Y. Liu, R. Fujimura, K. Ishida, N. Oya, N. Yoshie, T. Shimura and K. Kuroda, J. Phys. Chem. Solids, 2012, 73, 1136-1145.

37 N. C. Greenham, I. D. W. Samuel, G. R. Hayes, R. T. Phillips, Y. A. R. R. Kessener, S. C. Moratti, A. B. Holmes and R. H. Friend, Chem. Phys. Lett., 1995, 241, 89-96.

38 M. J. Frisch, G. W. Trucks, H. B. Schlegel, G. E. Scuseria, M. A. Robb, J. R. Cheeseman, G. Scalmani, V. Barone, G. A. Petersson, H. Nakatsuji, X. Li, M. Caricato, A. Marenich, J. Bloino, B. G. Janesko, R. Gomperts, B. Mennucci, H. P. Hratchian, J. V. Ortiz, A. F. Izmaylov, J. L. Sonnenberg, D. Williams-Young, F. Ding, F. Lipparini, F. Egidi, J. Goings, B. Peng, A. Petrone, T. Henderson, D. Ranasinghe, V. G. Zakrzewski, J. Gao, N. Rega, G. Zheng, W. Liang, M. Hada, M. Ehara, K. Toyota, R. Fukuda, J. Hasegawa, M. Ishida, T. Nakajima, Y. Honda, O. Kitao, H. Nakai, T. Vreven, K. Throssell, J. A. Montgomery Jr, J. E. Peralta, F. Ogliaro, M. Bearpark, J. J. Heyd, E. Brothers, K. N. Kudin, V. N. Staroverov, T. Keith, R. Kobayashi, J. Normand, K. Raghavachari, A. Rendell, J. C. Burant, S. S. Iyengar, J. Tomasi, M. Cossi, J. M. Millam, M. Klene, C. Adamo, R. Cammi, J. W. Ochterski, R. L. Martin, K. Morokuma, O. Farkas, J. B. Foresman and D. J. Fox, Gaussian 09, Gaussian, Inc., Wallingford CT, 2016.

39 J. Choi, D. Kim, B. Lee and J. H. Kim, Bull. Korean Chem. Soc., 2009, 30, 1933-1938.

40 Y. Halil, B. Küçüköz, G. Sevinç, S. Tekin, H. G. Yaglioglu, M. Hayval and A. Elmali, Dyes Pigm., 2013, 99, 979-985. 41 R. Saito and E. Ito, Heterocycles, 2010, 81, 2599-2608.
42 J. H. Gibbs, Z. Zhou, D. Kessel, F. R. Fronczek, S. Pakhomova and M. G. H. Vicente, J. Photochem. Photobiol., B, 2015, 145, 35-47.

43 W. Liu, A. Tang, J. Chen, Y. Wu, C. Zhan and J. Yao, ACS Appl. Mater. Interfaces, 2014, 6, 22496-22505.

44 P. E. Kesavan and I. Gupta, Dalton Trans., 2014, 43, 1240512413.

45 L. Gai, a H. Lu, B. Zou, G. Lai, Z. Shen and Z. Li, RSC Adv., 2012, 2, 8840-8846.

46 B. C. Popere, A. M. Della Pelle, A. Poe, G. Balaji and S. Thayumanavan, Chem. Sci., 2012, 3, 3093-3102.

47 S. Ru, Sol. Energy, 2016, 130, 139-147.

48 W. Shockley and H. J. Queisser, J. Appl. Phys., 2015, 510, 510519.

49 Y. Lin, Y. Li and X. Zhan, Chem. Sci., 2012, 4245-4272.

50 C. R. Lomas, Supramol. Chem., 2012, 24, 526-531.

51 S. D. Collins, C. M. Proctor, N. A. Ran and T. Nguyen, Adv. Energy Mater., 2016, 6, 1-11.

52 M. Azzouzi, J. Yan, T. Kirchartz, K. Liu, J. Wang, H. Wu and J. Nelson, Phys. Rev. X, 2018, 8, 31055.

53 A. B. Matheson, A. Ruseckas, S. J. Pearson and I. D. W. Samuel, Mater. Horiz., 2019, DOI: 10.1039/ c8mh01204k.

54 L. K. Jagadamma, M. T. Sajjad, V. Savikhin, M. F. Toney and I. D. W. Samuel, J. Mater. Chem. A, 2017, 5, 14646-14657.

55 C. J. Schaffer, C. M. Palumbiny, M. A. Niedermeier, C. Burger, G. Santoro, S. V Roth and P. Müller-buschbaum, Adv. Energy Mater., 2016, 1600712.

56 C. J. Schaffer, C. M. Palumbiny, M. A. Niedermeier, C. Jendrzejewski, G. Santoro, S. V Roth and P. Müllerbuschbaum, Adv. Mater., 2013, 25, 6760-6764. 